\title{
The antioxidant resveratrol down-regulates inflammation \\ in an in vitro model of Pseudomonas aeruginosa infection of lung epithelial cells
}

\author{
A thesis presented to \\ The Faculty of Graduate Studies \\ of \\ Lakehead University \\ by \\ ASHLEY M. CERQUEIRA
}

In partial fulfillment of requirements

for the degree of

Master of Science in Biology

September $19^{\text {th }}, 2012$

(C) Ashley M. Cerqueira, 2012 


\begin{abstract}
Pseudomonas aeruginosa is a Gram-negative opportunistic pathogen capable of infecting the lungs and causing severe pulmonary disease in immunocompromised individuals. During the infectious process, $P$. aeruginosa provokes a potent inflammatory response and induces the release of reactive oxygen species (ROS). Cells undergo oxidative stress when cellular antioxidants are unable to effectively scavenge and detoxify ROS resulting in lung damage. Resveratrol $\left(3,5,4^{\text {ee }}\right.$-trihydroxystilbene) is a natural polyphenolic compound with recognized antioxidant effects. In this study we have tested the hypothesis that the antioxidant activities of resveratrol can attenuate an inflammatory response in $P$. aeruginosa-infected cells. Human lung epithelial (A549) cells were pretreated with resveratrol for 5 hours followed by infection with $P$. aeruginosa in vitro. Intracellular ROS generation measured with $\mathrm{CM}-\mathrm{H}_{2}$ DCFDA was used as an indicator of P. aeruginosa-induced oxidative stress. Surface expression of Fas/CD95 and activation of caspases-3 and -7 were used as indicators of cellular apoptosis. To further study the effects of resveratrol we also measured protein expression of intercellular adhesion molecule (ICAM)-1 and gene expression of pattern recognition receptors and enzymes related to inflammation and redox signaling. Resveratrol significantly reduced ROS generation, ICAM-1 expression, human beta-defensin-2 expression, and markers of apoptosis in A549 cells infected with $P$. aeruginosa, and up-regulated levels of glutathione peroxidase, suggesting that this compound may play an important therapeutic role in protecting the lungs against the deleterious effects of $P$. aeruginosa infection.
\end{abstract}




\section{Lay Summary}

The Lakehead University Department of Biology lists its mission statement as: "Faculty and students in the Department of Biology are bound together by a common interest in explaining the diversity of life, the fit between form and function, and the distribution and abundance of organisms." This research project, centered in the realm of the human sciences, aims to understand the mechanisms behind Pseudomonas aeruginosa infection of immunocompromised lungs using an in vitro model, and suggests that resveratrol, an antioxidant component of several fruits, nuts, and red wines, is a natural therapeutic agent capable of protecting the lungs against damage during infection. 


\section{Acknowledgements}

As a first year Biology student walking onto campus for the first time I could not have imagined how important becoming involved with research would be to both my personal and professional development. My experiences in the Lakehead Biology Department, and most recently at the Northern Ontario School of Medicine (NOSM), have taught me many life lessons and awarded me many friends among my colleagues.

First and foremost I would like to thank my supervisor, Dr. Marina Ulanova, for her profound support and guidance throughout this entire process. She has been both a mentor and a friend, and has not only imparted onto me the virtues of working hard, but has inspired an unquenchable thirst for knowledge, and most importantly, instilled the significance of professional integrity. I could not have asked for a more thoughtful and encouraging supervisor, and I look forward to our continued collaboration throughout the next phase of my academic journey.

A true acknowledgment of the major influences that have helped me during this time would not be complete without the heartfelt recognition of thesis committee member Dr. Neelam Khaper. Her time and patience in instructing me has been greatly appreciated, and was paramount in building a solid foundation from which I could build my project on.

I would also like to thank Dr. Heidi Schraft who, in addition to being my third committee member, took me under her wing during my first foray into research as an undergraduate student. My experiences with Dr. Schraft opened many doors and were important in preparing me for my future research endeavors. For this I am eternally grateful. 
We have a good team of people here in the NOSM lab, and I wish to thank both the current and previous lab members that I have had the privilege of working with for their lively encouragement and patient troubleshooting sessions. These are the friendships that have helped to make these past two years a rewarding and enriching experience. A special thanks also goes out to the newest faculty member to join the NOSM team, Dr. Simon Lees, for his support and instruction in the lab. Finally, I would like to thank my family for their support, patience, and love. I also gratefully acknowledge the Natural Sciences and Engineering Research Council of Canada (NSERC), NOSM, and the Lakehead University Faculty of Graduate Studies and Department of Biology for funding. 


\section{Abbreviations}

\begin{tabular}{|c|c|}
\hline$\cdot \mathrm{OH}$ & Hydroxyl radical \\
\hline AP-1 & Activator protein-1 \\
\hline ATP & Adenosine triphosphate \\
\hline BALF & Bronchoalveolar lavage fluid \\
\hline BSA & Bovine serum albumin \\
\hline $\mathrm{CD}$ & Cluster of differentiation \\
\hline cDNA & Complementary deoxyribonucleic acid \\
\hline $\mathrm{CF}$ & Cystic Fibrosis \\
\hline $\mathrm{CM}-\mathrm{H}_{2} \mathrm{DCFDA}$ & $\begin{array}{l}\text { 5-(and-6)-chloromethyl-2',7'-dichlorodihydrofluorescein diacetate, } \\
\text { acetyl ester }\end{array}$ \\
\hline COPD & Chronic obstructive pulmonary disease \\
\hline $\mathrm{ddH}_{2} \mathrm{O}$ & Double-distilled water \\
\hline $\mathrm{EPO}$ & Eosinophil peroxidase \\
\hline FBS & Fetal bovine serum \\
\hline FLICA & Fluorochrome inhibitors of caspases \\
\hline GPx & Glutathione peroxidase \\
\hline GSH & Reduced glutathione \\
\hline GSR & Glutathione reductase \\
\hline GSSG & Glutathione disulphide (oxidized glutathione) \\
\hline $\mathrm{H}_{2} \mathrm{O}_{2}$ & Hydrogen peroxide \\
\hline HSLs & Homoserine lactones \\
\hline $\mathrm{IL}$ & Interleukin \\
\hline LPS & Lipopolysaccharide \\
\hline
\end{tabular}




\begin{tabular}{|c|c|}
\hline MPO & Myeloperoxidase \\
\hline mRNA & Messenger ribonucleic acid \\
\hline NADPH & Nicotinamide adenine dinucleotide phosphate \\
\hline $\mathrm{NF}-\kappa \mathrm{B}$ & Nuclear factor-kappaB \\
\hline NLR & Nucleotide binding and oligomerization domain-like receptor \\
\hline $\mathrm{O}_{2} \cdot-$ & Superoxide anion \\
\hline PAK & Pseudomonas aeruginosa strain $\mathrm{K}$ \\
\hline PBS & Phosphate buffered saline \\
\hline $\mathrm{qPCR}$ & Quantitative real-time polymerase chain reaction \\
\hline QS & Quorum sensing \\
\hline RNS & Reactive nitrogen species \\
\hline ROS & Reactive oxygen species \\
\hline SEM & Standard error of the mean \\
\hline SOD & Superoxide dismutase \\
\hline TNF & Tumour necrosis factor \\
\hline TNF- $\alpha$ & Tumour necrosis factor-alpha \\
\hline TNFR & Tumour necrosis factor receptor \\
\hline$\gamma$-GCS & Gamma-glutamylcysteine synthetase \\
\hline$\gamma-\mathrm{GT}$ & Gamma-glutamyl transpeptidase \\
\hline
\end{tabular}




\section{Table of Contents}

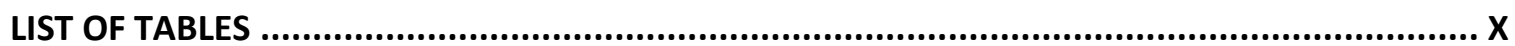

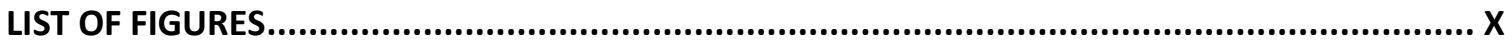

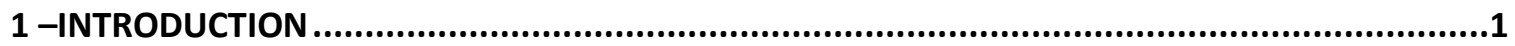

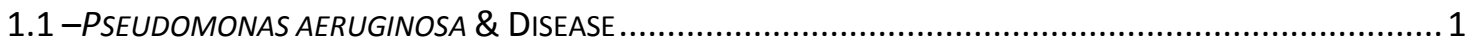

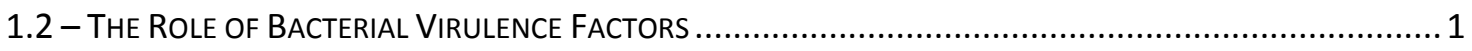

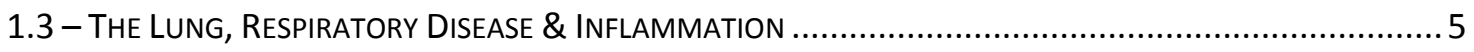

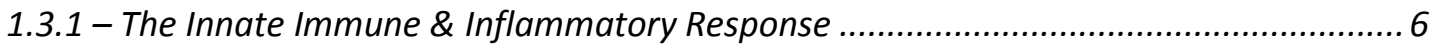

1.3.2 - The Role of Nod-like Receptors ................................................................................. 7

1.3.3 - Oxidant generation in the Airspace........................................................................... 8

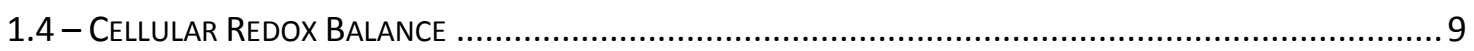

1.4 .1 - Reactive Oxygen Species ................................................................................... 9

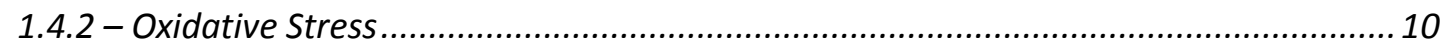

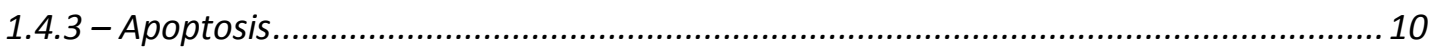

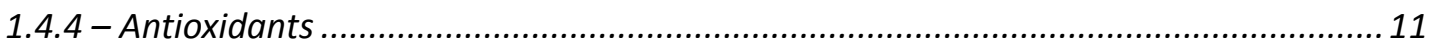

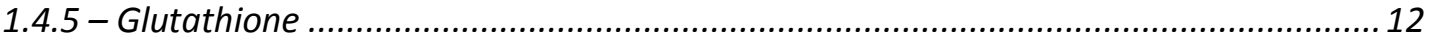

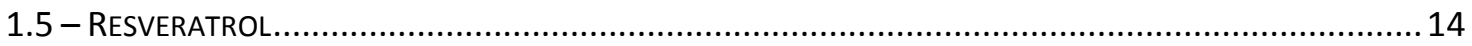

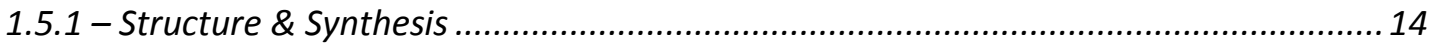

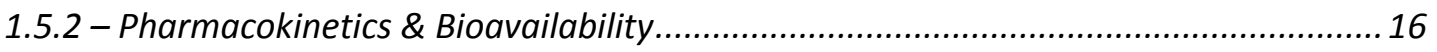

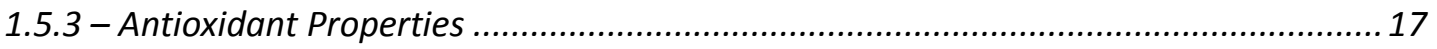

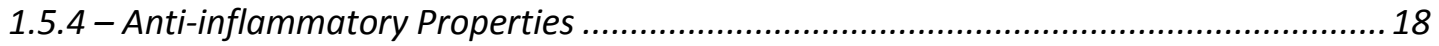

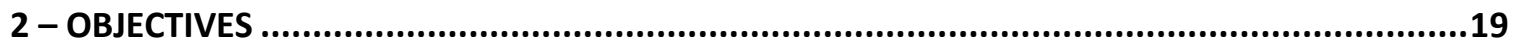

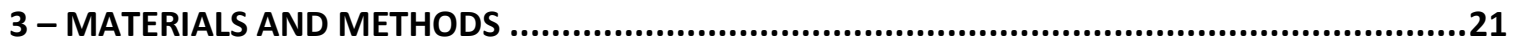

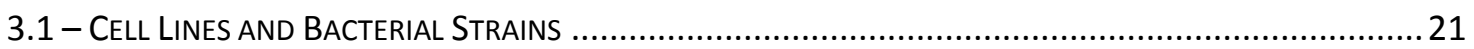

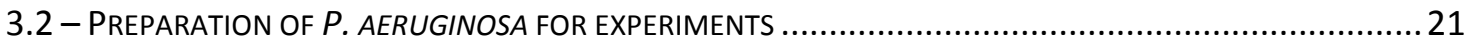

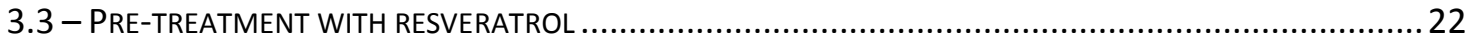

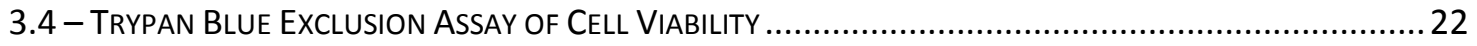

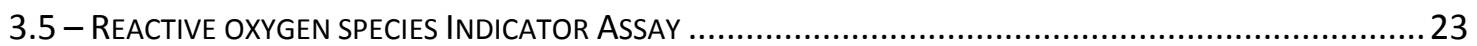

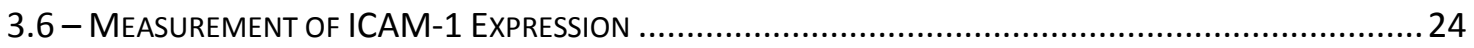




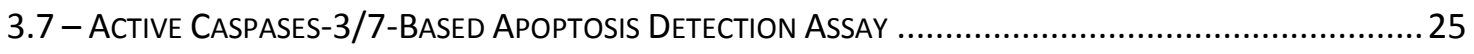

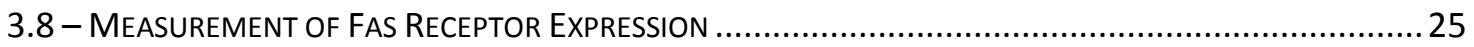

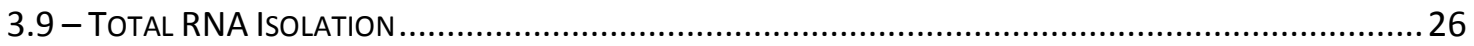

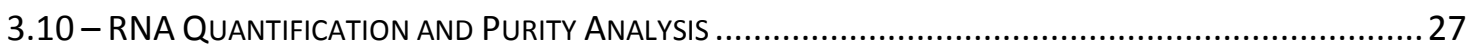

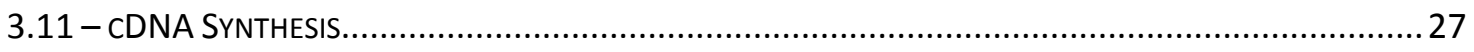

3.12 - Quantitative Real-Time Polymerase Chain Reaction................................................... 27

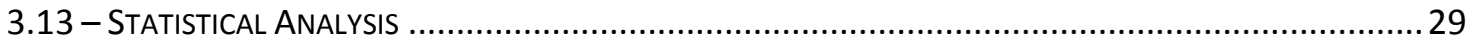

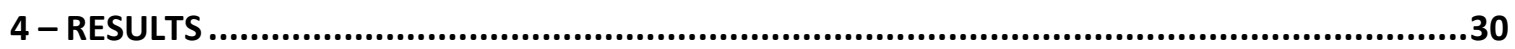

4.1 - RESVERATROL HAS NO EFFECT ON A549 CELL VIABILITY, BUT IS SENSITIVE TO SERUM .......................... 30

4.2 - RESVERATROL DOWN-REGULATES P. AERUGINOSA-INDUCED OXIDATIVE STRESS ................................ 30

4.3 - ReSVERATROL DOWN-REgULATES P. AERUGINOSA-INDUCED APOPTOSIS IN A549 CELLS .................... 31

4.4 - RESVERATROL REGULATES ICAM-1 SURFACE EXPRESSION ON A549 CELLS INFECTED WITH $P$.

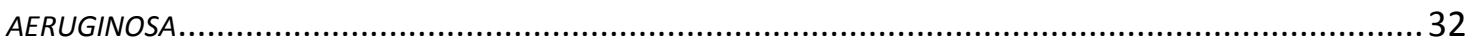

4.5 - RESVERATROL UP-REGULATES MRNA EXPRESSION OF GLUTATHIONE PEROXIDASE ........................... 32

4.6 - RESVERATROL DOWN-REGULATES MRNA EXPRESSION OF ANTIMICROBIAL PEPTIDES ........................ 33

4.7 - RESVERATROL UP-REGULATES MRNA EXPRESSION OF INTRACELLULAR PATHOGEN RECOGNITION

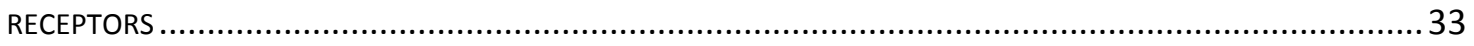

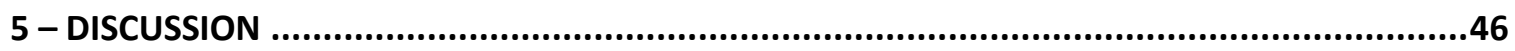

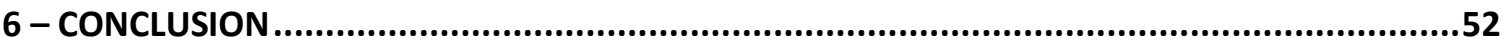

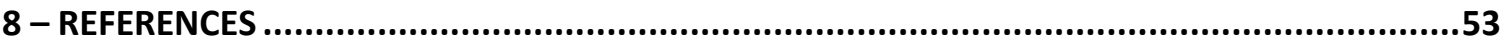




\section{List of Tables}

Table 1. Quantitative real-time PCR primers

\section{List of Figures}

Figure 1. The Intrinsic and Extrinsic Pathways of Apoptosis................................................... 13

Figure 2. Structure of resveratrol in both of its isometric forms.............................................. 15

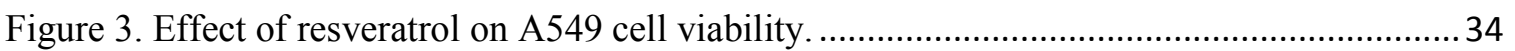

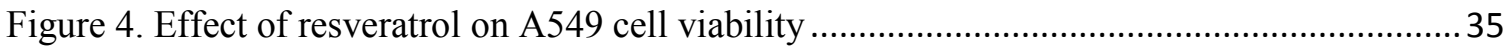

Figure 5. Effect of serum on the antioxidant capacity of resveratrol ...........................................36

Figure 6. Effect of resveratrol on intracellular ROS levels in A549 cells infected with $P$.

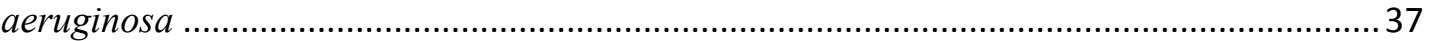

Figure 7. Effect of resveratrol pre-treatment on intracellular levels of bacteria-induced ROS ......38

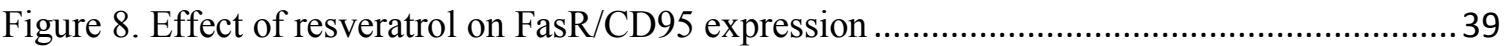

Figure 9. Effect of resveratrol on $P$. aeruginosa-induced apoptosis........................................... 40

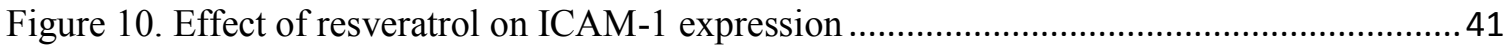

Figure 11. Effect of resveratrol on GPx mRNA expression in A549 cells infected with $P$.

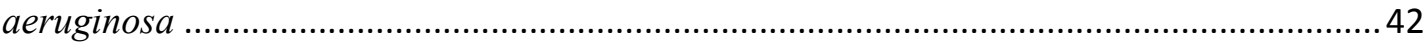

Figure 12. Effect of resveratrol on HBD-2 mRNA expression in A549 cells infected with $P$.

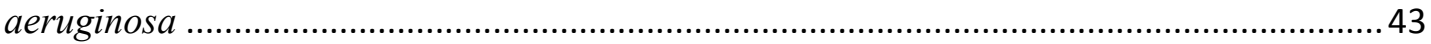

Figure 13. Effect of resveratrol on Nod1 mRNA expression in A549 cells infected with $P$. aeruginosa

Figure 14. Effect of resveratrol on Nod2 mRNA expression in A549 cells infected with $P$. aeruginosa 


\section{1 -Introduction}

\section{1 -Pseudomonas aeruginosa \& Disease}

Pseudomonas aeruginosa is a Gram negative, aerobic, rod-shaped bacterium responsible for a variety of acute and chronic infections. Infection by P. aeruginosa is predominantly seen in immunocompromised individuals, including patients with Cystic Fibrosis, HIV/AIDS, burn wound victims, transplant recipients, and patients undergoing chemotherapy (Kipnis et al. 2006; Sadikot et al. 2005). Its presence in nature is ubiquitous, and $P$. aeruginosa is capable of inhabiting almost any aqueous environment including soil, surface water, sewage, plants, and various foods including fruit and vegetables (Bonten et al. 1999). Found also within the sinks and humidifiers of health care settings, $P$. aeruginosa can be easily transferred to patients by hospital staff (Nseir et al. 2002) and as a result has become a common cause of nosocomial, or hospitalacquired, pneumonia, second only to Staphylococcus aureus (Santucci et al. 2003). Indeed, $P$. aeruginosa infection accounts for $10 \%$ of all hospital-acquired infections (Diekema et al. 1999) and approximately $25 \%$ of all ventilator-associated pneumonia (VAP), leading to a $69 \%$ mortality rate primarily due to septic shock following lung infection (Chastre et al. 2002; Crouch Brewer et al. 1996). Lung injury due to $P$. aeruginosa infection results from the direct destructive effects of the organism on the lung tissue and the potent host immune response (Sadikot et al. 2005).

\section{2 - The Role of Bacterial Virulence Factors}

To aid in its pathogenicity, $P$. aeruginosa is equipped with multiple virulence factors that allow it to adhere, invade, infect, and destroy human cells. P. aeruginosa can also form anaerobic bacterial communities called biofilms, which restrict the entry of 
antimicrobial compounds and provide a platform for the bacteria to produce virulence factors (Lau et al. 2004). This resourcefulness coupled with an easily mutable nature make $P$. aeruginosa an important pathogen capable of developing resistance against therapeutic agents targeting it. Indeed, $P$. aeruginosa is particularly difficult to eradicate (Kipnis et al. 2006; Lau et al. 2004).

$P$. aeruginosa utilize surface appendages, which play an important role in adhesion to cellular surfaces. A single monotrichous flagella serves to propel bacteria via corkscrew motions (Kipnis et al. 2006). These thick, hair-like protein structures also mediate adhesion by binding to glycoprotein asialo-GM1 (Kipnis et al. 2006). Flagella also interact with toll-like receptors (TLRs) 5 and 2 to stimulate pro-inflammatory cytokine production critical in initiating the inflammatory response. In the lung environment, $P$. aeruginosa adapts to its surroundings and loses some virulence factors (i.e. flagella), resulting in aflagellar mutants that are more adept at avoiding host innate immune response during chronic infection (Kipnis et al. 2006; Sadikot et al. 2005). Pili are smaller finger-like surface appendages that facilitate movement using a "twitching" movement to sweep over cellular surfaces. Pili also use the same asialo-GM1-dependant mechanism to adhere to cells, and both flagella and pili are under study as potential targets for specific therapy (Kipnis et al. 2006).

Within the outer membrane of $P$. aeruginosa lies lipopolysaccharide (LPS). Found in all Gram-negative bacteria, LPS is composed of a hydrophobic domain, Lipid A, located in the phospholipid bilayer and a complex consisting of a core polysaccharide and an O-specific polysaccharide (O-antigen), which together form the hydrophilic tail. LPS maintains structural integrity within the bacterial cell wall and protects against the 
effects of chemical attack (Kipnis et al. 2006). In particular, the O-antigen can be used to both distinguish between $P$. aeruginosa serotypes and to make vaccines. These vaccines, however, are of limited value because of the rate of genomic recombination and the high adaptability of the pathogen (Holloway 1955; Kipnis et al. 2006). It has also been observed that Lipid A composition changes in the process of airway colonization in $\mathrm{CF}$ patients. LPS is crucial to bacterial survival, and its removal leads to death of the pathogen (Ernst et al. 2003; Kipnis et al. 2006).

P. aeruginosa also utilizes a Type III secretion system (TTSS) to inject colonized cells with a variety of exotoxins. A syringe-like structure on the bacterial surface serves to inject effector proteins through the host cell membrane into the cytoplasm. Exotoxins of $P$. aeruginosa include ExoY, ExoS, ExoT, and ExoU, and while differing in their specific effects all are implicated in inflammation and cell death (Kipnis et al. 2006). ExoY compromises host membrane integrity by increasing cytoplasmic cAMP and host membrane permeability. ExoU possesses phospholipase A2 activity to destroy the host membrane and cause rapid necrotic death (Engel et al. 2009). ExoS and ExoT disrupt the structure of cytoplasm using N-terminal GTPase activating protein (GAP) domains that inhibit actin polymerization. ExoS also prevents normal cytoskeletal protein function by inhibiting interaction of Erzin-Radixin-Moesin, and ExoT prevents wound healing by inhibiting the Rac/integrin healing pathway (Kipnis et al. 2006).

Persistent inflammation is common in chronic P. aeruginosa infection of $\mathrm{CF}$ patients, and is partially caused by the Type II Secretion System (T2SS), which releases toxins and extracellular enzymes into the extracellular milieu. Including elastase and 
pyocyanin, these secretins are commonly implicated in pathogen invasion and tissue damage (Durand et al. 2003; Kipnis et al. 2006).

Pyocyanin is a blue/green-pigmented secondary metabolite secreted via T2SS, which plays a distinct role in the pathogenicity of $P$. aeruginosa. Effects of pyocyanin include the recruitment of neutrophils to the airway epithelia, prevention of apoptotic cell engulfment by macrophages, depression of host immune responses, and it also acts to increase production of interleukin (IL)-8 by host cells (Bianchi et al. 2008; Lau et al. 2004). Pyocyanin is also an oxireducer and inflicts oxidative-stress-related damage on host epithelial cells by oxidizing host antioxidants like glutathione (Kipnis et al. 2006).

Large volumes of pyocyanin are commonly seen in sputum samples from infected CF patients, however the impact of pyocyanin alone is difficult to determine as numerous virulence factors play different roles in P. aeruginosa pathogenicity (Kipnis et al. 2006). In vitro studies using purified pyocyanin demonstrated an extensive amount of cellular damage resulting from an inhibition of normal ciliary function, epidermal cell growth, and cell respiration. While antioxidant therapy has been shown to improve lung function in $\mathrm{CF}$ patients, inhibiting pyocyanin production is also a potential therapeutic strategy (Kipnis et al. 2006). In addition, increased levels of IL-8 are also seen when human airway epithelial cells undergo oxidative stress (Lau et al. 2004). This increase in IL-8 recruits pro-inflammatory cells through a chemical gradient, perpetuating inflammation (Lau et al. 2004; Vlahopoulos et al. 1999).

Quorum sensing (QS) is a sophisticated form of communication between bacterial cells and is found in both acute and chronic P. aeruginosa infections. QS recognizes lowweight signaling molecules called homoserine lactones (HSLs) (Winstanley et al. 2009). 
HSLs are secreted by $P$. aeruginosa and accumulate in the external environment as the pathogen persists and multiplies. Depending on the extracellular concentrations, $P$. aeruginosa can effectively coordinate the expression of other virulence factors like pyocyanin. Biofilm production is also cued via QS (Winstanley et al. 2009).

\section{3 - The Lung, Respiratory Disease \& Inflammation}

Composed of over 40 different cell types, the human lung is an organ responsible for respiration and is an active player in innate immunity and front-line defense against pathogens (Hippenstiel et al. 2006; Shek et al. 1994).The terminal ends of the respiratory tree are composed to alveolar epithelial cells, which are divided further into type I and type II cells(Evans et al. 2010; Hippenstiel et al. 2006).Type I cells are responsible for gas exchange in the lung between the air space and the capillaries, and while making up only $33 \%$ of the total number of alveolar epithelial cells, cover $93 \%$ of the alveolar surface area. Alveolar type II cells, on the other hand, are the precursors for type I cells and account for $67 \%$ of the total number of epithelial cells present in the lung, but cover only $7 \%$ of the alveolar surface area (Dinis-Oliveira et al. 2008; Evans et al. 2010). These cells facilitate water and ion transport, and the surfactant proteins secreted by type II cells act as a chemical barrier against foreign environmental particulates and help prevent lung collapse (Dinis-Oliveira et al. 2008; Shek et al. 1994).

The respiratory epithelium represents an important mucosal barrier and provides mucociliary clearance via tiny cilia that brush bacteria and debris upwards via wave-like motions where material can be diverted to the gastrointestinal tract and digested (Evans et al. 2010; Knowles et al. 2002). During lung infection, however, inflammatory responses can lead to severe impairment and dysfunction of the barrier properties within the 
endothelium and epithelium, leading to a disseminated, or systemic, response (Chow et al. 2003).

\subsection{1 - The Innate Immune \& Inflammatory Response}

An effective host response against $P$. aeruginosa infection requires a variety of

cell types and mediators in order to recognize, respond, and clear the bacteria from the airways (Sadikot et al. 2005). Almost immediately upon infectious insult, activation of the pulmonary endothelium and epithelium leads to the secretion of low-molecular weight signaling molecules, called cytokines (i.e. TNF- $\alpha$, IL-1 $\beta$, IL-6), which facilitate the activation of alveolar and interstitial macrophages; while a special class of cytokines with chemoattractant properties, called chemokines (i.e. IL-8), direct the transmigration of the activated macrophages into the alveolar space and sequester large amounts of neutrophils within the pulmonary microvasculature (Chow et al. 2003; Sadikot et al. 2005). Once recruited, these cells release a battery of cytotoxic and pro-inflammatory agents including proteolytic enzymes, reactive oxygen species, cationic proteins, lipid mediators, and more inflammatory cytokines (Chow et al. 2003).

The up-regulation of adhesion molecules is a step imperative to the inflammatory response, and allows activated macrophages and neutrophils to adhere tightly to the endothelial wall and move throughout the pulmonary epithelium (Chow et al. 2003; Sadikot et al. 2005). Currently, there are three recognized classes of adhesion molecules: integrins ( $\alpha$ - and $\beta$ - integrins), selectins (L-, P- and E-selectin), and the immunoglobulin superfamily of cell surface proteins (ICAM-1, VCAM-1) (Cavallaro et al. 2003). More specifically, intercellular adhesion molecule-1 (ICAM-1; CD54) is a transmembrane glycoprotein expressed constitutively on epithelial, endothelial and immune cells (Hogg et al. 1991); however, its expression increases during inflammation in response to 
cytokines such as TNF- $\alpha$, INF- $\gamma$, and IL-1(Dustin et al. 1988; Look et al. 1992). ICAM-1 is a ligand for the integrin LFA-1 (CD11a,b/CD18), that both facilitates leukocyte transmigration into tissues during inflammation and intercellular interactions (Krunkosky et al. 2000).

Responses to $P$. aeruginosa also involve innate chemical epithelial defense via the induction of low molecular weight antimicrobial peptides (Schroder et al. 1999), which demonstrate antimicrobial activity with a preference towards Gram-negative bacteria and yeasts (Schroder et al. 1999). These peptides are expressed almost immediately following contact with human epithelial cells, and function independently from leukocyte-mediated immune defense mechanisms (Schroder et al. 1999). In particular, human beta-defensin-2 (HBD-2) is a $5 \mathrm{kDa}$, highly cationic antimicrobial peptide produced on the surface of airway epithelial cells and within phagolysosomes in phagocytes, and functions to kill bacteria and fungi (Schroder et al. 1999).

\subsection{2 - The Role of Nod-like Receptors}

In addition to TLRs, the innate immune system also includes a class of pathogen recognition receptors called nucleotide binding and oligomerization domain-like receptors (NLRs) (Geddes et al. 2009). The human NLR family contains 23 known members to date, and is a large family of intracellular receptors that regulate both inflammation and apoptosis (Travassos et al. 2005). However, studies have only recently highlighted the importance of Nod1 and Nod2 in innate immune response and as a result they have become the best characterized members in the NLR family (Inohara et al. 2005). Where Nod1 recognizes diaminopimelic acid found in the peptidoglycan of many Gram-negative bacteria, Nod2 is more of a general sensor of bacteria and detects muramyl dipeptide present in the peptidoglycan of both Gram-positive and -negative 
bacteria (Girardin et al. 2003). As well, recognition of $P$. aeruginosa during infection has been traditionally associated with TLRs, however, following internalization $P$. aeruginosa still elicits an inflammatory response supporting the idea that the cell would be equipped with an internal sensor (Plotkowski et al. 1999). This is believed to be due to activation of Nod1, which has been shown to play a critical role in the TLR-independent activation of NF- $\mathrm{KB}$ during infection with Gram-negative bacteria like $P$. aeruginosa (Travassos et al. 2005), however, the role of Nod2 during infection remains unknown.

\subsection{3 - Oxidant generation in the Airspace}

Large evidence supports the role of oxidants and oxidative injury in the pathogenesis of lung infections (Chow et al. 2003). Following migration into the lungs, macrophages and neutrophils generate reactive oxygen species (ROS) in response to inflammatory mediators (Chow et al. 2003; Rahman et al. 2006). In particular, leukocyte activation generates the $\mathrm{O}_{2}$ - radical via the (NADPH) oxidase system; $\mathrm{O}_{2}$ - is quickly converted into $\mathrm{O}_{2}$ and $\mathrm{H}_{2} \mathrm{O}_{2}$ by superoxide dismutase (SOD) enzymes (Chow et al. 2003; Rahman et al. 2006). Phagocytic cells may also make use of other enzymes to produce ROS including myeloperoxidases (MPO) and eosinophil peroxidase (EPO) (Rahman et al. 2006). Eosinophils contribute to the oxidant burden significantly because these cells possess a greater capacity for $\mathrm{O}_{2}-$ and $\mathrm{H}_{2} \mathrm{O}_{2}$ production compared to neutrophils, and the amount of EPO in eosinophils is 3 to 10 times higher than the amount of MPO present in neutrophils. Another potent oxidant of considerable importance, $\cdot \mathrm{OH}$, is formed nonenzymatically in the presence of free iron $\left(\mathrm{Fe}^{2+}\right)$ via the Fenton reaction and immediately reacts with surrounding target molecules (Rahman et al. 2006). A diverse array of stimuli including LPS, cytokines, chemokines, complement fragments and lipid mediators are elevated during airway stress and stimulate neutrophil-produced ROS. 
During the infectious process, $P$. aeruginosa induces ROS production within epithelial cells in a few ways. Following its secretion into the microenvironment, pyocyanin permeates the epithelial cell membrane and directly oxidizes intracellular pools of NADPH and glutathione, producing superoxide and downstream ROS (Rada et al. 2011). Recognition of $P$. aeruginosa LPS by the epithelial cells leads to ROS production through protein kinase $\mathrm{C}$ (PKC)-NADPH oxidase signaling pathway in human epithelial cells (Yan et al. 2008). Other potential sources of ROS are derived from the activated epithelium itself via induction of the mitochondrial electron transport chain, cytochrome $\mathrm{P} 450$, and xanthine oxidase. In case of mechanical ventilation, the introduction of excess oxygen can also fuel the production of ROS (Chow et al. 2003). In acute lung injury, however, stimulated phagocytes produce the majority of ROS (Ward 2010). Overwhelming oxidant injury may lead to alveolar collapse and extensive fibrotic scarring, impairing gas exchange between the affected airways and the capillary system (Ward 2010).

\section{4 - Cellular Redox Balance}

\subsection{1 - Reactive Oxygen Species}

Reactive oxygen and nitrogen species (ROS, RNS) refer to a large group of free radicals derived from superoxide $\left(\mathrm{O}_{2}{ }^{-}\right)$or nitric oxide (NO), respectively, and include $\mathrm{O} 2 \cdot-$ and $\mathrm{NO}$, as well as hydrogen peroxide $\left(\mathrm{H}_{2} \mathrm{O}_{2}\right)$, the hydroxyl radical $(\cdot \mathrm{OH})$, hypochlorous acid ( $\mathrm{HOCl})$, peroxynitrite (ONOO), and ozone $\left(\mathrm{O}_{3}\right)$ (Park et al. 2009). Within the airway epithelium, ROS are formed endogenously through the reduction of molecular oxygen to water following mitochondrial electron transport as part of cellular 
respiration (Ciencewicki et al. 2008; Gram 1997; Mak 2008; Rahman et al. 2006). As well, cellular enzymes including cyclooxygenases, lipoxygenases, peroxidases, cytochrome P450 oxidase and xanthine oxidase can be released by activated inflammatory cells (Ciencewicki et al. 2008; Gram 1997; Mak 2008; Rahman et al. 2006). At moderate levels ROS, however, are essential for maintaining cellular homeostasis and play an important role in regulating many signal transduction pathways, often acting as second messengers (Bilska et al. 2005; Droge et al. 1994; Winrow et al. 1993).

\subsection{2 - Oxidative Stress}

Oxidative stress refers to an imbalance in the redox status of the cell favouring an oxidizing environment. Extensive ROS production leads to the depletion of antioxidants and results in cellular damage. In particular, ROS can damage DNA strands by reacting with base pairs and the deoxyribose phosphate backbone of DNA, a main target of radical damage (Gram 1997). Without the protection of antioxidants, ROS can also initiate lipid peroxidation of polyunsaturated fatty acid components of cell membrane phospholipids, affecting cellular integrity (Rahman et al. 2006). Amino acids can also be damaged by ROS, leading to protein denaturation and enzyme deactivation (Gram 1997; Rahman et al. 2006). When left unmanaged, oxidative stress can eventually lead to cell death.

\subsection{3 - Apoptosis}

Apoptosis refers to programmed cell death essential for the natural process of clearing unwanted or excess cells and can occur via one of two pathways, i.e. the Type I (extrinsic) and Type II (intrinsic) pathways (Kuribayashi et al. 2006) (Figure 1). The 
intrinsic pathway becomes activated following the loss of mitochondrial membrane potential causing the release of pro-apoptotic factors, like cytochrome $c$, from the inner membrane space into the cytoplasm. Upon the release of cytochrome $c$, intracellular cysteine proteases called caspases are activated which lead to the activation of downstream effector caspases-3 and -7 (Kuribayashi et al. 2006).

Similarly, activation of the death receptor Fas (FasR, CD95) also leads to apoptosis. Following activation, Fas/CD95 aggregates with the FADD adaptor protein, where procaspase- 8 is recruited and cleaved in a signaling cascade ultimately leading to the activation of caspases-3 and -7 (Barnhart et al. 2003).

\subsection{4 - Antioxidants}

In order to cope with oxidant attack, intricately equipped antioxidant systems provide a mechanism to detoxify and maintain lung redox balance in vivo. Currently, there are two recognized classes of antioxidants: enzymatic and non-enzymatic. Enzymatic antioxidants degrade ROS to less toxic molecules, and include catalase, superoxide dismutase, glutathione peroxidase, glutathione reductase, and the thioredoxins (Mak 2008; Rahman et al. 2006). Non-enzymatic antioxidants can interact directly with ROS to regulate their levels, and are regulated by feedback mechanisms such that balanced levels of both antioxidants and ROS are maintained in the cell (Mak 2008; Rahman et al. 2006). Examples include ascorbic acid, $\alpha$-tocopherol, $\beta$-carotene, melatonin, and low molecular-weight thiol-containing compounds (i.e. the reduced form of glutathione) (Mak 2008; Rahman et al. 2006). 


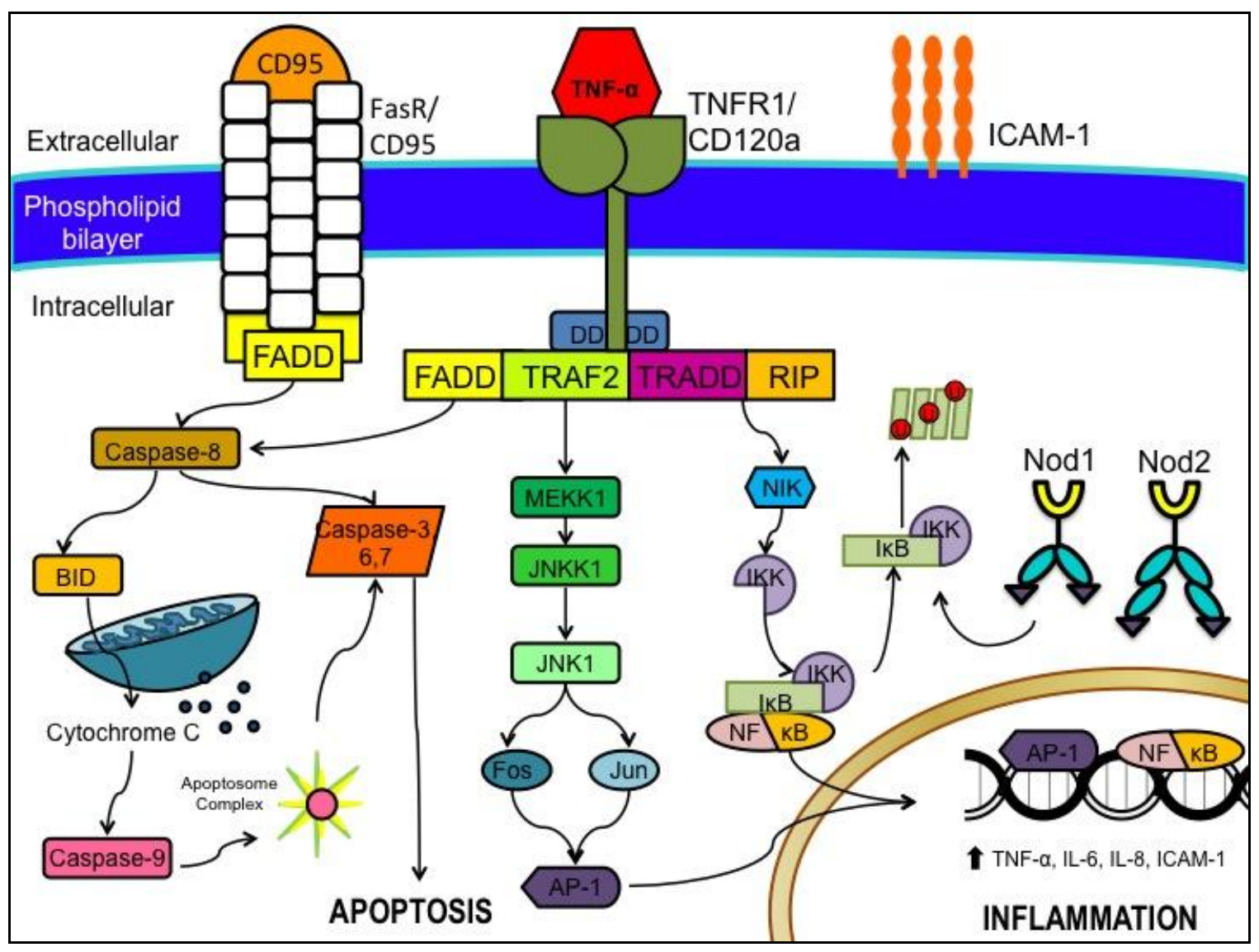

Figure 1. The Intrinsic and Extrinsic Pathways of Apoptosis. The extrinsic apoptosis pathway is triggered by the activation of death receptors which initiate caspase- 8 activation. Caspase-8, in turn, activates caspases-3 and -7leading to apoptosis. In the intrinsic apoptosis pathway, apoptotic stimuli trigger the release of cytochrome $c$ from the mitochondria independent of caspase-8, leading to the formation of the apoptosome complex and activate caspases-3 and -7 .

\subsection{5 - Glutathione}

Glutathione (GSH), a ubiquitous thiol-containing tripeptide (L- $\gamma$-glutamyl-Lcysteinyl-glycine), is the most important antioxidant in terms of ROS detoxification and plays a vital role in protecting the airspaces and epithelial cells against oxidants in the extracellular milieu (Droge et al. 1994; Rahman et al. 2000). Compared to plasma levels 
that typically range from $1-10 \mathrm{mM}, \mathrm{GSH}$ is present in greater concentration in the epithelial lining fluid and is also involved in maintaining lung epithelial cell membrane integrity against the deleterious effects of ROS (Haddad 2004; Rahman 2005; Rahman et al. 2000). Depletion of GSH in epithelial cells is associated with loss of barrier function and increased permeability (Li et al. 1994; Li et al. 1996).

The synthesis of GSH requires the enzymes $\gamma$-glutamylcysteine synthetase $(\gamma$ GCS) and GSH synthetase as well as the amino acids glycine, cysteine, and glutamic acid. The GSH tripeptide is formed by the consecutive actions of $\gamma$-GCS and GSH synthetase (Rahman et al. 2000). Acting either intra- or extracellularly, GSH scavenges lipid peroxidases, $\mathrm{H}_{2} \mathrm{O}_{2}$, and other radicals in a reaction catalyzed by glutathione peroxidase (GPx). Ultimately, this reaction generates an oxidized form of GSH called glutathione disulphide (GSSG). Once formed, GSSG can then be reduced back into GSH by the enzyme GSH reductase (GSR) as part of the GSH redox couple. Alternatively, resynthesis of GSH may also take place on the outer cell surface via $\gamma$-glutamyl transpeptidase ( $\gamma$-GT), an enzyme found in the plasma membrane and, in particular, on lung epithelial cells. $\gamma$-GT cleaves extracellular GSH into a $\gamma$-glutamyl moiety along with its constituent amino acids and is transferred to an appropriate amino acid receptor where they are transported into the cell and salvaged into reformed GSH. It has also been suggested that plasma GSH may undergo direct uptake into type II epithelial cells but the mechanism remains controversial (Deneke et al. 1989; Rahman et al. 1996). 


\section{5 - Resveratrol}

Resveratrol (trans-3,4“5-trihydroxystilbene) is a non-flavanoid, polyphenolic compound found in a variety of plant species present in the human diet, and specifically can be found in relatively at high concentrations in grapes (Vitis spp.), berries (Vaccinium spp.), and peanuts (Arachis spp.) (Wood et al. 2010). Known to be an active constituent in at least 72 plant species, resveratrol is also a phytoalexin, synthesized in response to fungal, viral, and bacterial attacks, and/or exposure to ultraviolet (UV) radiation (Ignatowicz et al. 2001; Pervaiz 2003; G. J. Soleas et al. 2001; Wood et al. 2010). Recently, resveratrol has been of intense focus in a number of studies, demonstrating an array of beneficial effects in diseases of nervous, gastrointestinal, and respiratory systems, and it has also been shown to have cardio-protective and anti-cancer properties (Fremont 2000; Pervaiz 2003).

\subsection{1 - Structure \& Synthesis}

Resveratrol is made up of two phenol rings linked by a styrene double bond, with cis- and trans-isomersization facilitated by UV exposure (Figure 2) (Wood et al. 2010). Of these two isomers, trans-resveratrol displays greater steric stability when protected from high $\mathrm{pH}$ and light, and for this reason much less is known about the pharmacological effects of the cis-resveratrol isomer (Leiro et al. 2004). 


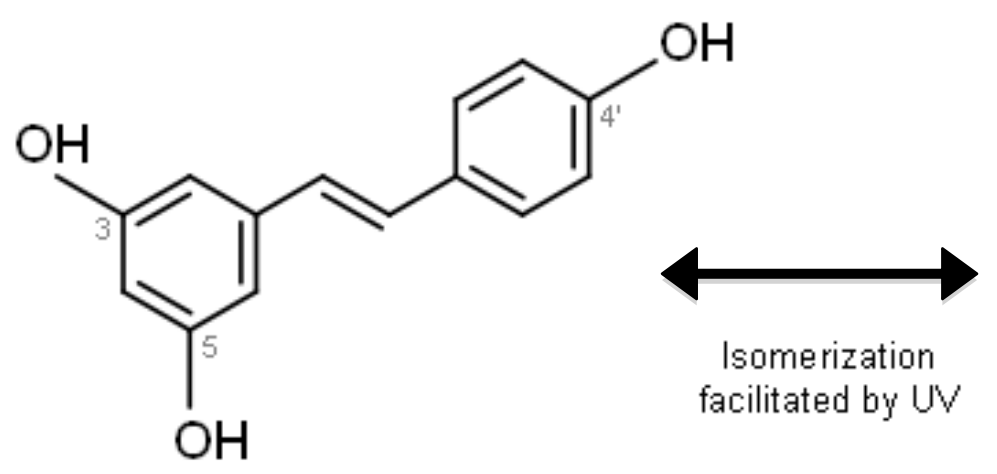

trans-Resveratrol

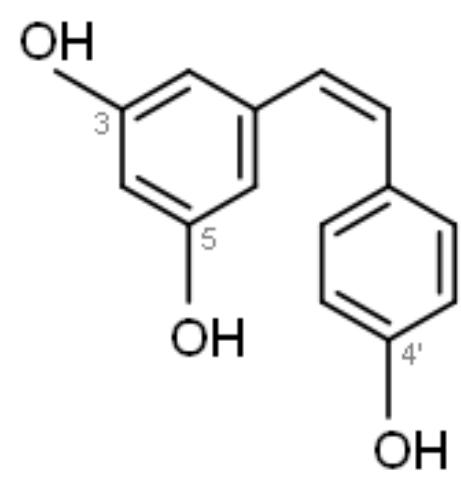

cis-Resveratrol

Figure 2. The structure of resveratrol in both of its isometric forms.

Synthesis of resveratrol takes place in the leaf epidermis and stalks of the plant, as well as the kernels and skin (pericarp) of the grape berries, but not in the flesh itself (Creasy 1988; Langcake 1976). The amount of resveratrol in the skin of fresh grapes is heavily dependent upon the species variety, but typically ranges from $50-100 \mu \mathrm{g} / \mathrm{g}$ (Jeandet 1991). The higher content of the stilbene in red wines is a consequence of longer contact time (several days) between the berry skin and the must, compared to white wine where the must is immediately removed from the berry residue (Daniel et al. 1999). Consequently, the concentration of resveratrol in red wines is in the range of $1.5-3 \mathrm{mg} / \mathrm{L}$ (Goldberg 1995; Romero-Perez et al. 1996), with lower levels also being found in white and rose wines (Romero-Perez et al. 1996; Vrhovsek et al. 1995). In grape juice, resveratrol is found in substantially lower amounts, typically ranging from 3-15 $\mu \mathrm{g} / \mathrm{L}$ (G. Soleas et al. 1995).

Indeed, the consumption of resveratrol in many red wines is believed to be linked to the paradoxical observation of low mortality rates due to coronary heart disease in France despite a high incidence of risk factors including smoking, a diet rich in saturated fats, and a general lack of exercise (Soleas et al. 1997b). This phenomenon is referred to 
as the "French paradox", which suggests that moderate amounts of red wine (consuming 150-300 mL/day) is the root of this paradox (Renaud et al. 1992). The possible mechanisms for resveratrol cardioprotective activity involve its effect on lipid metabolism and platelet function, and the inflammatory mediators, alteration of eicosanoid synthesis, or inhibition of activated immune cells, such as neutrophils and monocytes/macrophages (Hao et al. 2004; Ignatowicz et al. 2001).

\subsection{2 - Pharmacokinetics \& Bioavailability}

To date, much of the information surrounding the pharmacokinetics and bioavailability of resveratrol is inconclusive and contradictory. In vivo studies using mice, rats, and dog models, however, suggest that resveratrol is absorbed satisfactorily in the gastrointestinal tract, with significant concentrations being found in the blood and a number of internal organs (Bertelli et al. 2001). The molecule itself has a relatively short half-life of approximately 8-14 minutes (Baur et al. 2006; Marier et al. 2002) and is rapidly metabolized by extensive first-pass metabolism where it becomes sulphated in the liver and intestinal epithelial cell (Bertelli et al. 2001; Goldberg 1995; Soleas et al. 2001; Vitrac et al. 2003; Yu et al. 2009). Indeed, this process may be important for the biological effects of resveratrol as studies by Kaldas et al. (2003), which showed that sulphate conjugation was imperative for resveratrol transport in the human intestinal epithelial cell line Caco-2. Moreover, resveratrol administered intravenously was found to be converted into a sulphate conjugate within 30 minutes in humans (Walle et al. 2004). The same study also found that the serum half-life of total resveratrol was $\sim 9.2$ hours, suggesting that exposure to modified forms of resveratrol may be higher compared to the original molecule. 
In another study of resveratrol oral bioavailability an average of $77.6 \mu \mathrm{M}$ resveratrol was measured in the urine of healthy volunteers following the intake of a $25 \mathrm{mg}(110 \mu \mathrm{M})$ resveratrol supplement (Walle et al. 2004), suggesting that much of the resveratrol taken up orally is excreted from the body. Therefore, it is more reasonable to suggest that in terms of our study, and at a clinical level, the doses of resveratrol needed to exert the effects here would require alternate routes of administration.

New therapeutic strategies are currently under development to help bypass metabolic breakdown of resveratrol. Resveratrol-containing lozenges, for example, have been found to increase buccal absorption of resveratrol (Asensi et al. 2002), and administration of resveratrol via injection may be another potential therapeutic tool in bypassing intestinal metabolism (Lu et al. 2009). Nanoparticles and liposome use are also being investigated as potential carriers of resveratrol (Santos et al. 2011).

\subsection{3 - Antioxidant Properties}

As previously discussed, an important relationship exists between ROS and the development of oxidative stress. Polyphenolic compounds are known to boast a variety of antioxidant effects stemming the redox properties associated with their phenolic hydroxyl groups and the resulting potential for electron delocalization within the chemical structure (Alarcon de la Lastra et al. 2007; Lopez-Velez et al. 2003). Current evidence suggests that in addition to acting as a free radical scavenger (Soleas et al. 1997a), resveratrol promotes the activity of several endogenous antioxidant defense enzymes. Indeed, in the non-small-cell lung carcinoma cell line, A549, resveratrol was shown to induce transcription of GPx, thioredoxin reductase (TrxR), and mitochondrial SOD (Hu et al. 2007). 


\subsection{4 - Anti-inflammatory Properties}

Many of the beneficial effects reported for resveratrol are attributed to an antiinflammatory effect observed in relation to a variety of inflammatory diseases. During inflammation, vascular permeability allows for the extravasation of leukocytes and inflammatory mediators out of capillaries and into the tissue. Resveratrol, however, has been shown to reduce vascular leakage induced by TNF- $\alpha$ (Fulgenzi et al. 2001). Resveratrol has also been found to down-regulate cytokine release in lung epithelial A549 cells, including IL-8 and GM-CSF (Donnelly et al. 2004). This is partially due to the fact that resveratrol can modulate activity of specific transcription factors, including nuclear factor-kappa (NF-kB) and activator protein (AP)-1, associated with inflammation (Donnelly et al. 2004; Wood et al. 2010).

Other potential anti-inflammatory effects of resveratrol include inhibition of synthesis and release of pro-inflammatory mediators, modification of eicosanoid synthesis, inhibition of active immune cells, and inflammatory enzymes such as iNOS and COX-2 through its inhibitory effect on NF- $\mathrm{kB}$ and AP-1 (Alarcon de la Lastra et al. 2007). Although the effects of resveratrol have been studied in several models of inflammation including LPS stimulation (Ferrero et al. 1998; Manna et al. 2000), viral infections, and allergies (Wood et al. 2010), no studies have explored its effects on inflammation in a model of bacterial infection. 


\section{2 - Objectives}

\section{Rationale:}

- Pseudomonas aeruginosa causes serious lung infection in immunosuppressed patients.

- Infection with P. aeruginosa will increase ROS production and inflammatory markers in infected lung epithelial cells in vitro.

- During the infectious process, oxidative stress and inflammation are interrelated and therefore a decrease in ROS levels by antioxidants will have an inhibitory effect on inflammatory pathways.

\section{Research Hypothesis}

Resveratrol will demonstrate anti-inflammatory effects in a model of inflammation caused by $P$. aeruginosa as a result of its antioxidant properties. 


\section{Objectives:}

1. Determine an appropriate range of resveratrol pre-treatment conditions for an epithelial cell line to assess its effect in an in vitro model of P. aeruginosa infection. This can be done by measuring cell viability following pre-treatment with resveratrol.

2. Determine which concentration of resveratrol demonstrates the strongest antioxidant effect by the assessing intracellular ROS-production resulting from $P$. aeruginosa-induced oxidative stress.

3. Examine the anti-apoptotic effect of resveratrol.

4. Examine the anti-inflammatory effect of resveratrol.

5. Examine the effect of resveratrol on select molecular markers of the cellular antioxidant and innate immune systems. 


\section{3 - Materials and Methods}

\section{1 - Cell Lines and Bacterial Strains}

The A549 human type II alveolar cell line (ATCC \# CCL-185) was used between passage numbers of 5-15. A549 cells were maintained in Dulbecco"s modified Eagle"s medium (DMEM) nutrient mixture F-12 Ham (Sigma-Aldrich, Oakville, ON, Canada) supplemented with $10 \%$ heat inactivated fetal bovine serum (FBS, SAFC Biosciences, Lenexa, KS) and 1\% L-glutamine (Gibco, Carlsbad, CA) without antibiotics. Cells were grown at $37^{\circ} \mathrm{C}$ with $5 \% \mathrm{CO}_{2}$ and seeded every $2-3$ days when confluency neared $80 \%$. A549 cells were seeded in T-25 $\mathrm{cm}^{2}$ flasks (Corning Incorporated, NY, USA) for 48 hours, which corresponded approximately to $2.4 \times 10^{6}$ cells/flask, unless otherwise stated.

Pseudomonas aeruginosa strain K (PAK) was kindly provided by Dr. RJ Irvin, University of Alberta, Edmonton. Bacterial cultures were maintained on sterile Luria Burtani (LB) medium (Fischer Scientific, Fair Lawn, NJ) with 1\% agar (LBA). Unless otherwise stated, infection times were used based on experimental conditions previously optimized in our lab. Generally, shorter infection times (i.e. 4 hours or less) were used when measuring markers involved in cellular signaling, while longer infection times (i.e. 18 hours) were needed when measuring protein structures that required more time for actual assemblage.

\section{2 - Preparation of $P$, aeruginosa for experiments}

A single colony of PAK was grown overnight in sterile LB medium at $37^{\circ} \mathrm{C}$ on a shaking platform at $150 \mathrm{rpm}$. Cultures were diluted by a factor of 20 into fresh LB medium and allowed to grow for approximately 1 hour or until mid-log phase when optical density at $600 \mathrm{~nm}\left(\mathrm{OD}_{600}\right)$ reached 0.3 . Bacteria were then centrifuged at $3500 \times$ 
$g$, for 20 minutes at $4^{\circ} \mathrm{C}$ and washed twice in sterile phosphate-buffered saline (PBS, pH 7.4). Following the final resuspension, bacteria were diluted to an $\mathrm{OD}_{600}$ of 0.30 in sterile serum-free DMEM F-12 Ham corresponding approximately to $2 \times 10^{8} \mathrm{CFU} / \mathrm{mL}$ as confirmed by serial dilutions and drop plating on LBA. From this stock, bacteria were added to cells at a multiplicity of infection (MOI) of either 50:1 or 100:1.

\section{3 - Pre-treatment with resveratrol}

A549 cells were grown in sterile serum-supplemented media for 48 hours to achieve $80 \%$ confluency. The medium was removed and the cells were washed with sterile PBS. Trans-Resveratrol (Sigma-Aldrich, Oakville, ON) was dissolved in 95\% ethanol to produce a $60 \mathrm{mM}$ stock solution and then was added to adherent A549 cells in serum-free media to achieve $100 \mu \mathrm{M}$, which was deemed to exert the strongest antioxidant effect after preliminary optimizational studies. The cells were incubated in the presence of resveratrol for the indicated time $\left(37^{\circ} \mathrm{C}, 5 \% \mathrm{CO}_{2}\right)$, and then washed twice with PBS, and used for experiments. Treatment with resveratrol did not have an effect on cell viability as determined using the Trypan blue exclusion assay run either with the ViCell XR Cell Viability Analyzer (Beckman Coulter, Mississauga, ON, CA) or by manual counting using a Nikon eclipse 50i phase-contrast microscope (Nikon Canada, Winnipeg, CA) and a Phase Micro 3200 Bright-Line hemocytometer (Hausser Scientific, Horsham, PA, USA). Resveratrol stock solutions were stored at $-20^{\circ} \mathrm{C}$ in the dark.

\section{4 - Trypan Blue Exclusion Assay of Cell Viability}

The Trypan blue exclusion method was used to measure both viability and number of A549 cells; it is based on the principle that in dead or dying cells a loss of membrane integrity allows for entry of the stain. Viable cells are seen in a microscope 
with a clear cytoplasm while membrane-compromised cells have a distinct blue colour in the cytoplasm. Viable cell counts were performed via the Trypan Blue Exclusion assay using a Vi-Cell XR Cell Viability Analyzer (Beckman Coulter), wherein $0.6 \mathrm{~mL}$ of diluted cell suspensions were mixed with Trypan Blue reagent. Cell counts were automatically assessed via 50 individual sub-samples measured using the Vi-Cell XR Cell Viability Analyzer software, and the total viable cell count was used when passaging or standardizing cell samples for experimentation.

\section{5 - Reactive oxygen species Indicator Assay}

To detect intracellular ROS, we used CM- ${ }_{2}$ DCFDA (5-(and-6)-chloromethyl$2^{\prime}, 7^{\prime}$-dichlorodihydrofluorescein diacetate, acetyl ester), a fluorescent due that diffuses passively through the cell membrane and is retained in viable cells. As oxidation occurs in the cell, esterase cleavage of the lipophilic blocking groups yields a charged form of the dye that is more effectively retained in the cell compared to the parent compound. As well, the thiol-reactive chloromethyl deriviative of $\mathrm{H}_{2}$ DCFDA used here boasts enhanced covalent binding to intracellular components, permitting even longer retention of the fluorescent adduct within the cell (as described by Invitrogen).

To measure intracellular ROS production, A549 cells were seeded onto flatbottom 6 well plates (Corning) and grown until $80 \%$ confluency. Adherent cells were pre-treated with resveratrol as previously described and/or infected with P. aeruginosa at a MOI of 50:1 or 100:1 for 1 hour as these conditions had been previously optimized in our lab (Hawdon et al. 2010). Cells were washed and stained with $500 \mu \mathrm{L}$ of $100 \mu \mathrm{M}$ CM- $\mathrm{H}_{2}$ DCFDA (Invitrogen Molecular Probes, Eugene, OR), and incubated for 30 minutes at $37^{\circ} \mathrm{C}$ in the dark, following the manufacturer"s protocol. After incubation, 
cells were washed with sterile $37^{\circ} \mathrm{C}$ PBS and $1 \mathrm{~mL}$ of fresh serum-free media was added, followed by another incubation for 30 minutes at $37^{\circ} \mathrm{C}$ in the dark. Stained cells were detached from the plate surface using disposable sterile cell scrapers (Fisher Scientific), washed twice, and resuspended in $500 \mu \mathrm{L}$ PBS followed by flow cytometric analysis. The BD FACSCalibur Flow Cytometer (BD Biosciences) together with BD CellQuest Pro Software were used in the assessment of fluorescent probes via flow cytometry. For each experiment a minimum of 10,000 gated events were acquired per trial. The mean fluorescent intensity (MFI) in the FL-1 Channel was deemed to be directly proportional to levels of intracellular ROS.

\section{6 - Measurement of ICAM-1 Expression}

Confluent A549 cells were pre-treated with resveratrol as described, and either stimulated for 18 hours with $10 \mathrm{ng} / \mathrm{mL}$ TNF- $\alpha$ or infected with $P$. aeruginosa at a MOI of 50:1 for 1 hour followed by incubation with medium containing $10 \mu \mathrm{g} / \mathrm{mL}$ polymyxin B (Sigma-Aldrich) for 17 hours to kill the bacteria as per previously established methods (Hawdon et al. 2010). The expression of ICAM-1 was determined using immunostaining with phycoerythrin (PE)-conjugated monoclonal antibody (mAb) against ICAM-1 (Mouse anti-human CD54, BD Pharmingen, Mississauga, ON). After 18-hour long incubation, cells were washed and detached using 0.5\% Trypsin-EDTA (Gibco, Eugene, OR). The cells were resuspended in $100 \mu \mathrm{L}$ of $0.1 \%$ BSA-PBS containing antibodies at a dilution of 1:50 and incubated for 1 hour at $4^{\circ} \mathrm{C}$. Following incubation, cells were washed twice with PBS and analyzed by flow cytometry (FL-2 channel). The data were expressed as relative mean fluorescence intensity (MFI), which was calculated by normalizing all fluorescence values to the untreated, labeled control. 


\section{7 - Active Caspases-3/7-Based Apoptosis Detection Assay}

For analysis of apoptosis, adherent A549 cells were infected with P. aeruginosa at an MOI of 50:1 for 2 hours, then detached and washed as described above. Apoptosis was measured by the presence of active caspase- 3 and caspase-7, detected by the CaspaTag caspase-3,7 in situ assay kit (Chemicon International, Temecula, CA) according to the manufacturer"s protocol and previously established methods (Hawdon et al. 2010). In this approach, a cell-permeable, carboxyfluorescein-labeled fluoromethyl ketone peptide inhibitor, fluorochrome inhibitors of caspases (FLICA), covalently binds to a reactive cysteine residue that resides on the large subunit of the active caspase heterodimer, thereby inhibiting further enzymatic activity. The bound labeled reagent is retained within the cell, while any unbound reagent diffuses out of the cell and is washed away. The resulting green fluorescent signal is measured via flow cytometry on the FL-1 channel. The data were expressed as \% caspase-positive cells, with gating of cell populations based on their forward and side scatter properties.

\section{8 - Measurement of Fas Receptor Expression}

Confluent cells were infected with $P$. aeruginosa at a MOI of 50:1 for 1 hour followed by incubation with medium containing $10 \mu \mathrm{g} / \mathrm{mL}$ polymyxin B (Sigma-Aldrich) for 17 hours to kill the bacteria, following the infection conditions outlined above. The cell-surface expression of FasR was determined using immunostaining with FITC mAb against FasR (Mouse anti-human CD95, BD Pharmingen, Mississauga, ON). After infection, cells were washed and detached using 0.5\% Trypsin-EDTA (Gibco, Eugene, OR). The cells were resuspended in $100 \mu \mathrm{L}$ of $0.1 \%$ BSA-PBS containing antibodies at a dilution of 1:50 and incubated for 18 hours at $4^{\circ} \mathrm{C}$. Following incubation, cells were washed twice with PBS and analyzed by flow cytometry (FL-1 channel). The data were 
expressed as relative mean fluorescence intensity (MFI), which was calculated by normalizing all fluorescence values to the untreated, labeled control.

\section{9 - Total RNA Isolation}

A549 cells were seeded onto T-25 $\mathrm{cm}^{2}$ tissue culture flasks, grown for 48 hours to $\sim 80 \%$ confluency, and incubated in serum- and antibiotic-free medium in the presence of $100 \mu \mathrm{M}$ resveratrol for 5 hours, followed by infection with P. aeruginosa at a MOI of 50:1 in serum-free media for 3 hours. This infection time for our model was based on optimization studies showing a stronger effect on gene expression levels compared to longer or shorter infection times. Adherent cells were washed once with sterile $37^{\circ} \mathrm{C}$ PBS and detached via trypsinization. Cells were collected and centrifuged at $1000 \times g$ for 5 min at $4{ }^{\circ} \mathrm{C}$, resuspended in $1.5 \mathrm{~mL}$ PBS and placed on ice. RNA isolation was performed using the Aurum Total RNA Mini kit (Bio-Rad) in accordance with the manufacturer"s instructions using certified RNase-free barrier tips (Ambion, Foster City, CA, USA). Cells were lysed using the provided lysis buffer and total RNA was extracted using a silica membrane spin column placed within RNase-free microfuge tubes. To avoid contamination by genomic DNA, salts, and other cellular protein components, DNase I digest was added to the columns at room temperature followed by several washes. A volume of $40 \mu \mathrm{L}$ of low ionic strength elution buffer was used to collect the pure RNA from the column. Of the total extracted volume, $5 \mu \mathrm{L}$ was placed into RNase-free $100 \mu \mathrm{L}$ tubes and used immediately to quantify extracted RNA while the remaining aliquots were stored at $-80^{\circ} \mathrm{C}$ for further use. 


\subsection{0 - RNA Quantification and Purity Analysis}

The concentration and integrity of extracted RNA was assessed using the Experion RNA StdSens kit (Bio-Rad) on an Experion Automated Electrophoresis Station (Bio-Rad) supported by Experion software (Bio-Rad) in accordance with the manufacturer"s instructions. Briefly, $1 \mu \mathrm{L}$ aliquots of denatured RNA samples and ladder were loaded onto an Experion RNA StdSens chip where 18 and 28 S rRNA peaks were measured. Only high-quality (i.e. 9+ RNA quality index, as per automatic Experion software calculation) RNA samples were used for subsequent gene expression analysis.

\subsection{1 - cDNA Synthesis}

First strand complementary DNA (cDNA) synthesis reactions were performed using the RevertAid H Minus First Strand cDNA Synthesis kit (Fermentas, Flamborough, ON, Canada) in accordance with the manufacturer"s instructions. To help preserve the quality of the RNA during cDNA synthesis the kit contained two important features: a reverse transcriptase with a point mutation that prevents RNA hydrolysis by RNase $\mathrm{H}$, and RNase inhibitor to further protect against RNA degradation. Briefly, RNA samples were mixed with oligo(dT)18 primers and the other kit components and incubated at $42^{\circ} \mathrm{C}$ for 1 hour before terminating the reaction by heating at $70^{\circ} \mathrm{C}$ for 5 minutes. The resultant products were either stored on ice and used immediately or placed at $-20^{\circ} \mathrm{C}$ for short-term storage.

\subsection{2 - Quantitative Real-Time Polymerase Chain Reaction} Quantitative real-time PCR (qPCR) was performed using primers for several genes as noted in Table 1 (SABiosciences, Frederick, MD, USA) and SYBR Green RT ${ }^{2}$ qPCR Master Mix (SABiosciences) with iQ5 Multicolor Real-Time PCR Detection System (Bio-Rad) in accordance with the manufacturer"s instructions. Briefly, $8 \mu \mathrm{L}$ of 
nuclease-free $\mathrm{ddH}_{2} \mathrm{O}$ was pipetted into the wells of a sterile 96-well PCR plate (Bio-Rad), followed by $1 \mu \mathrm{L}$ of primer, and $1 \mu \mathrm{L}$ of cDNA template. Due to its photosensitive nature, $10 \mu \mathrm{L}$ of the $2 \times$ Master Mix was added to the wells last and the plate was sealed using Microseal „B' $\mathrm{B}^{\mathrm{ec}}$ Film (Bio-Rad). Following iQ5 calibration, qPCR analysis of triplicate samples was performed using a two-step cycling program involving an initial single cycle of $95^{\circ} \mathrm{C}$ for 10 minutes to activate the DNA polymerase, followed by 40 cycles of $95^{\circ} \mathrm{C}$ for 15 seconds and $60^{\circ} \mathrm{C}$ for 1 minute. Following the qPCR reaction, a first derivative dissociation curve was performed as a quality control measure. Briefly, the reaction was heated to $95^{\circ} \mathrm{C}$ for $1 \mathrm{~min}$, cooled to $65^{\circ} \mathrm{C}$ for $2 \mathrm{~min}$, then ramped from 65 to $95^{\circ} \mathrm{C}$ at a rate of $2^{\circ} \mathrm{C}$ per minute. The formation of a single peak at temperatures greater than $80^{\circ} \mathrm{C}$ indicated the presence of a single PCR product in the reaction mixture. Gene expression was normalized to the reference gene GAPDH, which was found to be more consistent than $\beta 2$-microglobulin. 


\begin{tabular}{|c|c|c|c|c|c|}
\hline Gene name & UniGene \# & $\begin{array}{c}\text { RefSeq } \\
\text { Accession \# }\end{array}$ & $\begin{array}{l}\text { Band Size } \\
\text { (bp) }\end{array}$ & $\begin{array}{l}\text { Reference } \\
\text { Position }\end{array}$ & Source \\
\hline NOD1 & Hs. 405153 & NM_006092 & 144 & 4060 & SABiosciences \\
\hline NOD2 & Hs.592072 & NM_022162 & 141 & 4424 & SABiosciences \\
\hline Human $\beta$-defensin 2 & Hs.105924 & NM_004942 & 92 & 170 & SABiosciences \\
\hline $\begin{array}{l}\text { Human Glutathione } \\
\text { peroxidase } 1\end{array}$ & Hs.76686 & NM_000581 & 169 & 772 & SABiosciences \\
\hline Human GAPDH & Hs. 592355 & NM_002046 & 175 & 1287 & SABiosciences \\
\hline$\beta 2$-microglobulin & Hs. 534255 & NM_004048 & 114 & 381 & SABiosciences \\
\hline
\end{tabular}

Table 1.Quantitative real-time PCR primers. These primer sets were used as per manufactureres instructions, as described above.

\subsection{3 - Statistical Analysis}

Data were presented as mean \pm standard error of the mean (SEM) and are representative of $\mathrm{n} \geq 3$ independent experiments. In studies involving gene expression analysis, comparison of sample means was completed using one-way ANOVA with post hoc Tukey"s test, otherwise one-tailed Student"s t-test was applied. A p-value $<0.05$ was considered significant. GraphPad Prism 5.01 (GraphPad Software Inc, San Diego, CA) was used for the analysis. The use of asterisks denotes significant according to the following scheme: ${ }^{*} p<0.05 ; * * p<0.01 ; * * * p<0.001$. 


\section{4 - Results}

\section{1 - Resveratrol has no effect on A549 cell viability, but is sensitive to}

serum

To optimize the conditions of resveratrol pretreatment, A549 cells were treated with $5,10,50,100 \mu \mathrm{M}$ resveratrol for $1,4,5,12$, and 24 hours. Following the treatment, cell viability was assessed using the Trypan blue exclusion assay either through automated trypan blue staining (Figure 3) or manual hemocytometer counting (Figure 4) to ensure accuracy of both techniques. For all time points and concentrations used, viability of A549 cells remained above 90\% suggesting that resveratrol exerted no harmful or cytotoxic effects.

To further optimize our model, A549 cells were pre-treated with resveratrol in serum-containing and serum-free media (Figure 5). In our experiments, we observed a significant increase in intracellular ROS levels in A549 cells following 1 hour of PAK infection. Resveratrol pre-treatment in serum-containing media caused a significant decrease in ROS produced by A549 cells, while cells pre-treated in serum-free media displayed an even stronger decrease in ROS production. Indeed, serum-free pretreatment with resveratrol resulted in a 50\% decrease in ROS produced by A549 cells. For this reason subsequent pre-treatments were carried out in serum-free conditions.

\section{2 - Resveratrol down-regulates $P$, aeruginosa-induced oxidative stress ROS production by infected cells have been implicated in both inflammation and} tissue damage during $P$. aeruginosa infection (Ciofu et al. 2005). In agreement with previous findings in our lab (Hawdon et al. 2010), we observed a significant increase in ROS levels in A549 cells (Figures 6 \& 7) following 1 hour of PAK infection. Resveratrol pre-treatment for 4 hours at concentrations of $100 \mu \mathrm{M}$ and $200 \mu \mathrm{M}$, but not 
$10 \mu \mathrm{M}$ caused a significant decrease in post-infection ROS production in A549 cells (Figure 6). A stronger inhibitory effect towards ROS production, however, was noted after 5 hours of resveratrol pre-treatment (Figure 7). As well, an increased MOI of 100:1 was found to yield increased resolution in terms of ROS production. These findings suggest that under the conditions of $P$. aeruginosa infection, resveratrol pre-treatment was able to protect A549 cells from oxidative stress.

\section{3 - Resveratrol down-regulates $P$. aeruginosa-induced apoptosis in}

\section{A549 cells}

$P$. aeruginosa can induce apoptosis of infected airway epithelial cells via activation of the pro-apoptotic death receptor Fas/CD95 (Grassme et al. 2000) in a caspase- 8 dependent mechanism culminating in the activation of executioner caspases-3 and -7 (Lakhani et al. 2006; Mizuta et al. 2008). Thus, surface expression of the death receptor Fas/CD95, and levels of active caspases-3 and -7 were used as measures of apoptosis. Following methods previously optimized in our lab (Hawdon et al. 2010), surface expression of Fas/CD95 was up-regulated after 1 hour of PAK infection with a 17 hour polymyxin B co-incubation (Figure 8). After 2 hours, infected A549 cells contained significant levels of active caspases-3/7 (Figure 9). Resveratrol pre-treatment prior to infection caused a significant decrease in both Fas/CD95 surface expression (Figure 8) and caspase activity (Figure 9). Hence, our results show that pre-treatment of A549 cells with resveratrol can decreased apoptosis of cells caused by P. aeruginosa. 


\section{4 - Resveratrol regulates ICAM-1 surface expression on A549 cells}

infected with $P$, aeruginosa

Under conditions of inflammation and oxidative stress during $P$. aeruginosa infection, airways epithelial cells increase the expression of cellular adhesion molecules, like ICAM-1, that can facilitate leukocyte adhesion (Aldallal et al. 2002; Hawdon et al. 2010). In our experiments, 1 hour $P$. aeruginosa infection with 17 hour polymyxin B coincubation caused a significant increase in surface ICAM-1 expression on A549 cells (Figure 10). As a positive control, A549 cells were also stimulated with TNF- $\alpha$, a known inducer of ICAM-1 expression on airway epithelial cells (Krunkosky et al. 2000), at a concentration of $10 \mathrm{ng} / \mathrm{mL}$ for 18 hours. Resveratrol pre-treatment prior to P. aeruginosa infection or TNF- $\alpha$ stimulation caused a significant decrease in ICAM-1 expression. These findings suggest that infection with $P$. aeruginosa may stimulate inflammatory responses, like ICAM-1 expression, following a similar mechanism as TNF- $\alpha$ and that resveratrol down-regulates these inflammatory responses.

\section{5 - Resveratrol up-regulates mRNA expression of glutathione peroxidase}

Oxidative stress has been shown to retard antioxidant activity of enzymes like glutathione peroxidase (GPx), which is used by glutathione to catalyze the reaction of hydrogen peroxide into water (Rahman et al. 2000). Thus, our next goal was to determine if resveratrol could indirectly boost cellular antioxidant defense via the effect on GPx gene expression. No change in GPx expression was observed in A549 cells infected for 3 hours with $P$. aeruginosa (Figure 11). However, GPx gene expression was significantly up-regulated in both untreated control and resveratrol-pre-treated cells. Hence, our data indicate that pre-treatment of $P$. aeruginosa-infected A549 cells with resveratrol can increase cellular antioxidant defense. 


\section{6 - Resveratrol down-regulates mRNA expression of antimicrobial peptides}

Expression of the antimicrobial peptide, human beta-defensin-2 (HBD-2), can be rapidly induced during a PAK-stimulated inflammatory response (Diamond et al. 2000; Harder et al. 2000; Huang et al. 2007; Wehkamp et al. 2006). Indeed, we observed a significant increase in HBD-2 mRNA expression in A549 cells following 3 hours of infection with $P$. aeruginosa (Figure 12). Resveratrol pre-treatment caused significant decrease in HBD-2 mRNA transcription post-infection in A549 cells, suggesting that resveratrol may also impact innate immunity during infection.

\section{7 - Resveratrol up-regulates mRNA expression of intracellular pathogen recognition receptors}

Nod-like receptors, including Nod1 and Nod2, are intracellular pattern recognition receptors that regulate inflammatory and innate immune responses by responding to specific peptidoglycan motifs present in the bacterial cell wall (Delbridge et al. 2007). Nod1 and Nod2 respond to specific peptidoglycan motifs within the bacterial cell in a fashion similar to Toll-like receptor (TLR)-mediated cellular activation.

In our experiments, infection with $P$. aeruginosa did not have any noticeable effect on Nod1 and Nod2 mRNA expression (Figure $13 \&$ 14). Pre-treatment with resveratrol prior to infection was found to induce increases in both Nod1 and Nod2 mRNA expression. While the effect of resveratrol on Nod-like receptor activity had not been reported previously, it appears that resveratrol may modulate the expression of these receptors during $P$. aeruginosa infection. 

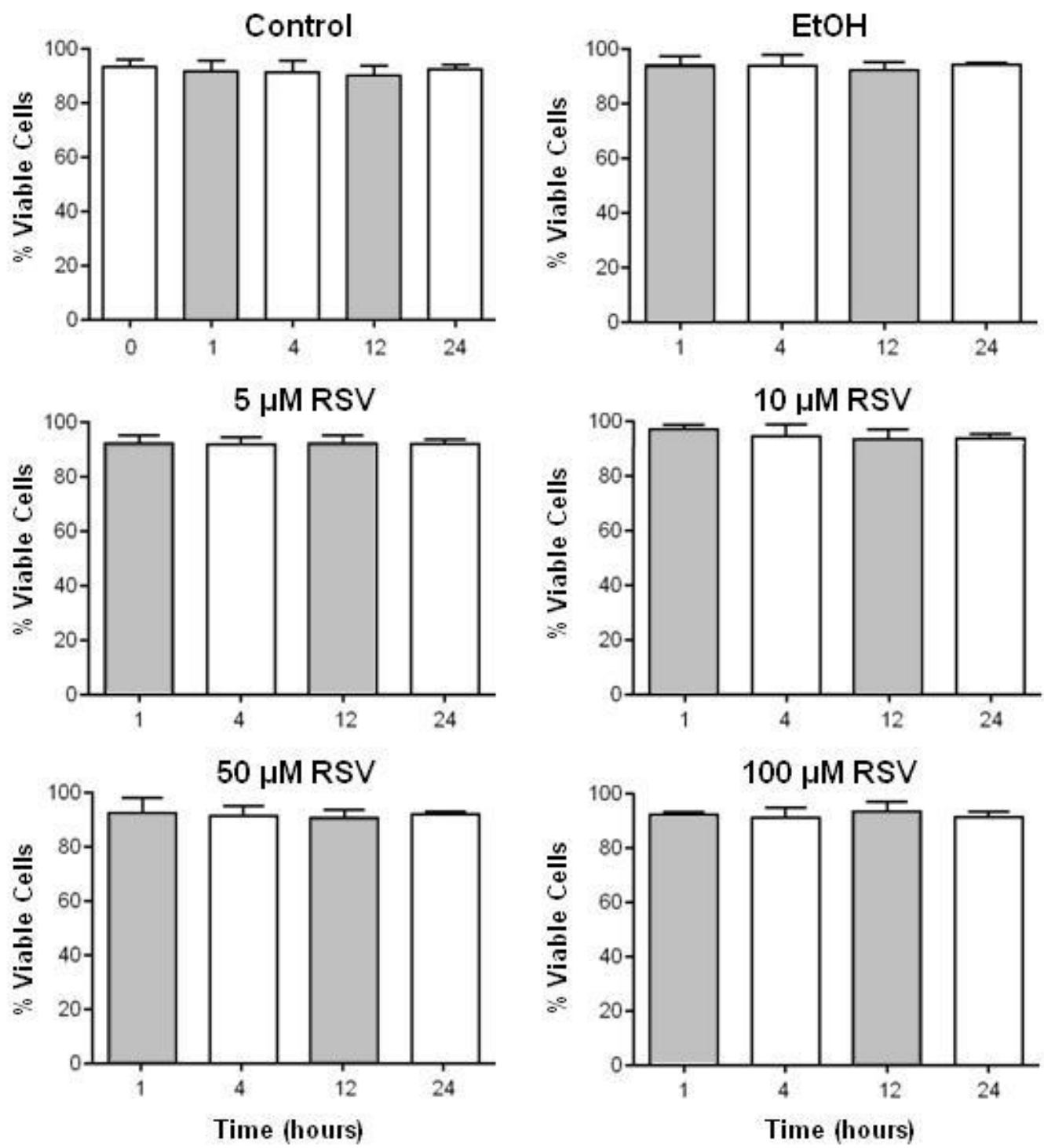

Figure 3. Effect of resveratrol on A549 cell viability. Viability of A549 cells was assessed via automated Trypan blue assay and counting. Cells were seeded onto 6-well plates, grown overnight to $\sim 80 \%$ confluence, and incubated in serum- and antibiotic-free medium in the presence of resveratrol for $1,4,12$ or 24 hours. Bars represent mean \pm SEM of 3 independent experiments. No statistical significance between samples was found. 

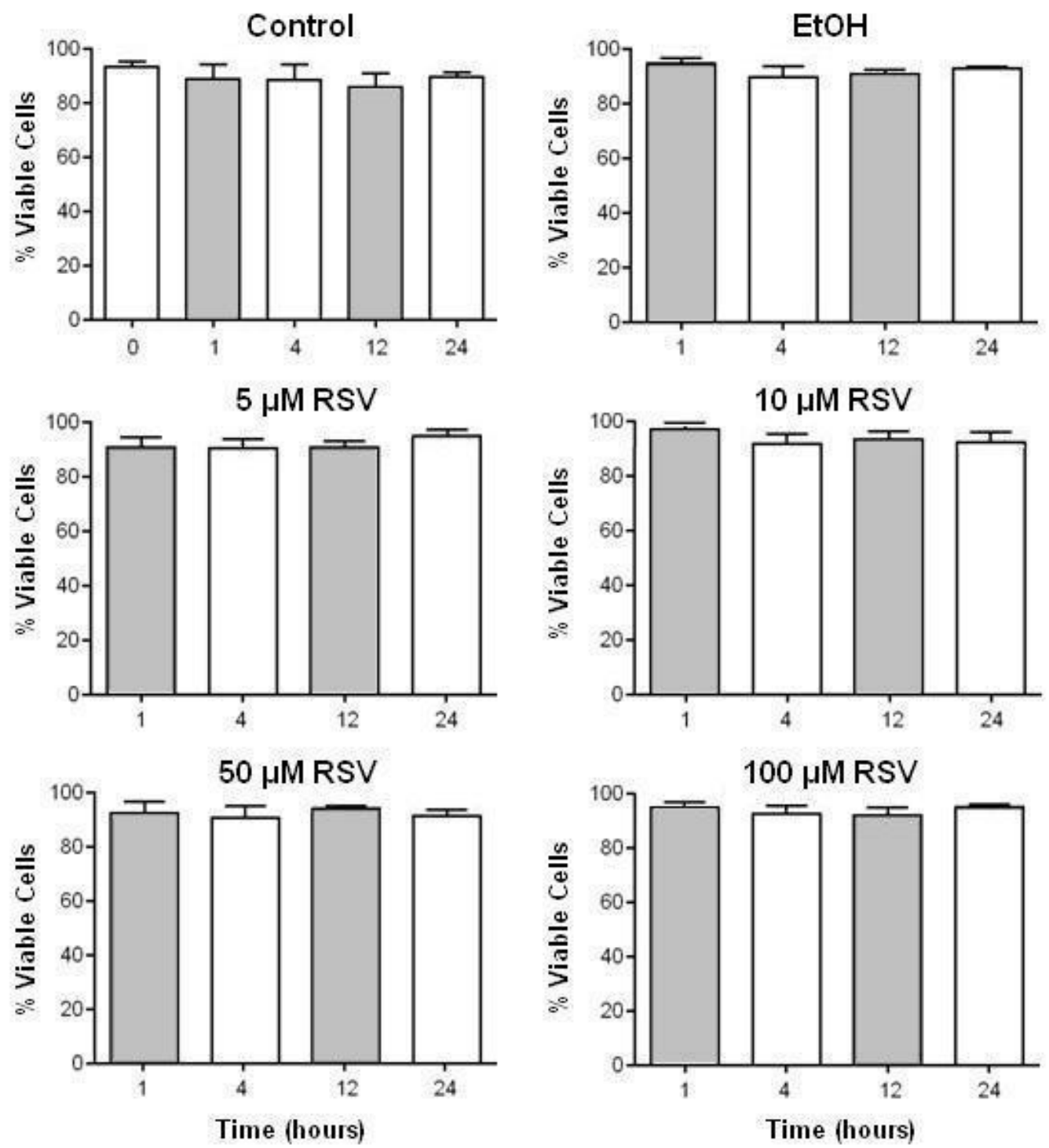

Figure 4. Effect of resveratrol on A549 cell viability. Viability of A549 cells was assessed via Trypan blue assay and manual counting with a haemocytometer. Cells were seeded onto 6-well plates, grown overnight to $\sim 80 \%$ confluence, and incubated in serumfree medium in the presence of resveratrol for $1,4,12$ or 24 hours. Bars represent mean \pm SEM of 3 independent experiments. No statistical significance between samples was found. 


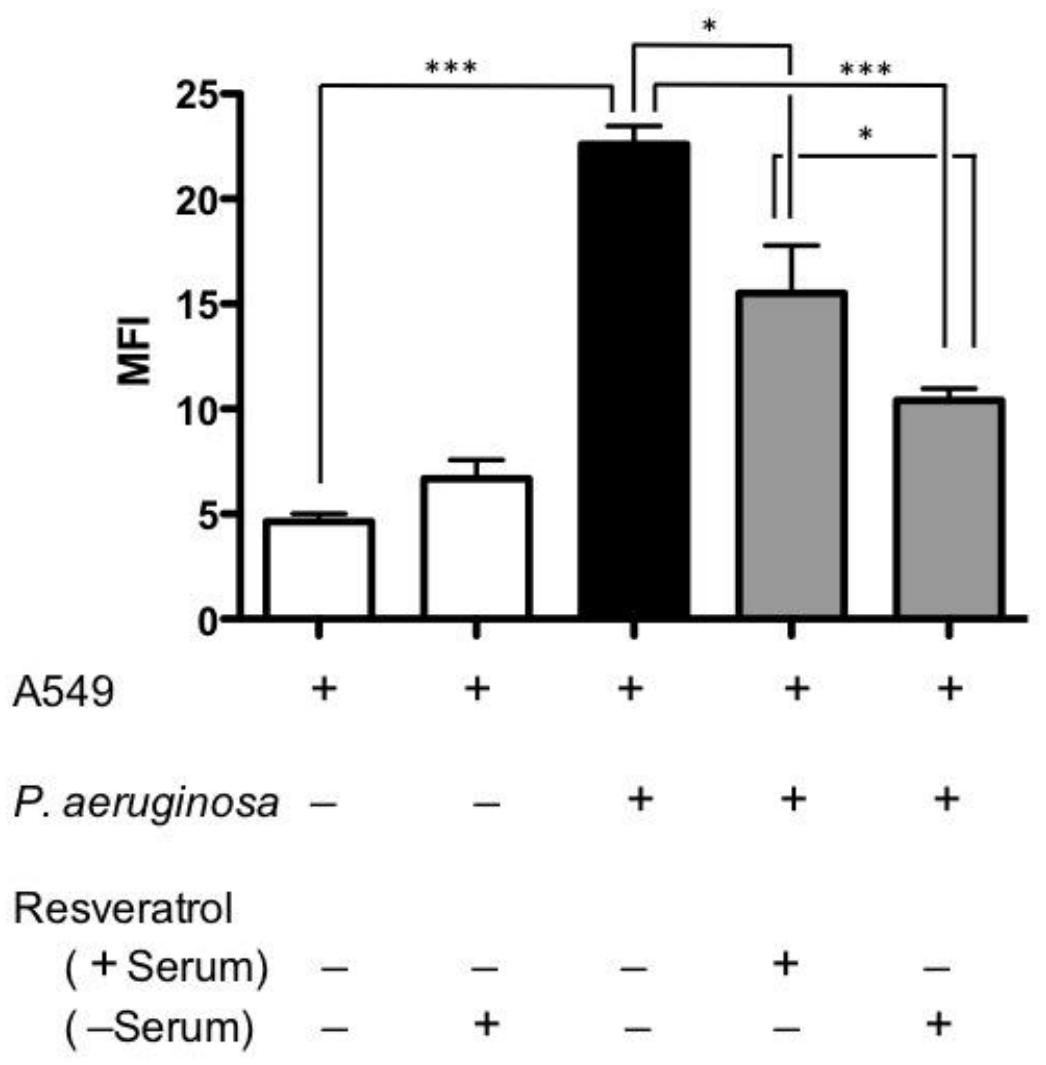

Figure 5. Effect of serum on the antioxidant capacity of resveratrol. Intracellular ROS levels in A549 cells were assessed using the $\mathrm{CM}-\mathrm{H}_{2}$ DCFDA assay. Cells were seeded onto 6 -well plates, grown overnight to $\sim 80 \%$ confluence, and pre-treated with 100 $\mu \mathrm{M}$ resveratrol in either serum-containing or serum-free media for 4 hours followed by infection with $P$. aeruginosa MOI 50:1 for 1 hour. Cells were then incubated with the fluorescent label for 30 minutes in order to ascertain the final redox environment of the cells, and a minimum of $1 \times 10^{4}$ gated events were analyzed via flow cytometry (FL-1 Channel). Bars represent mean \pm SEM of 3 independent experiments. $\left({ }^{*} p<0.05, * * * p<0.001 ; \mathrm{MFI}\right.$, mean fluorescence intensity) 


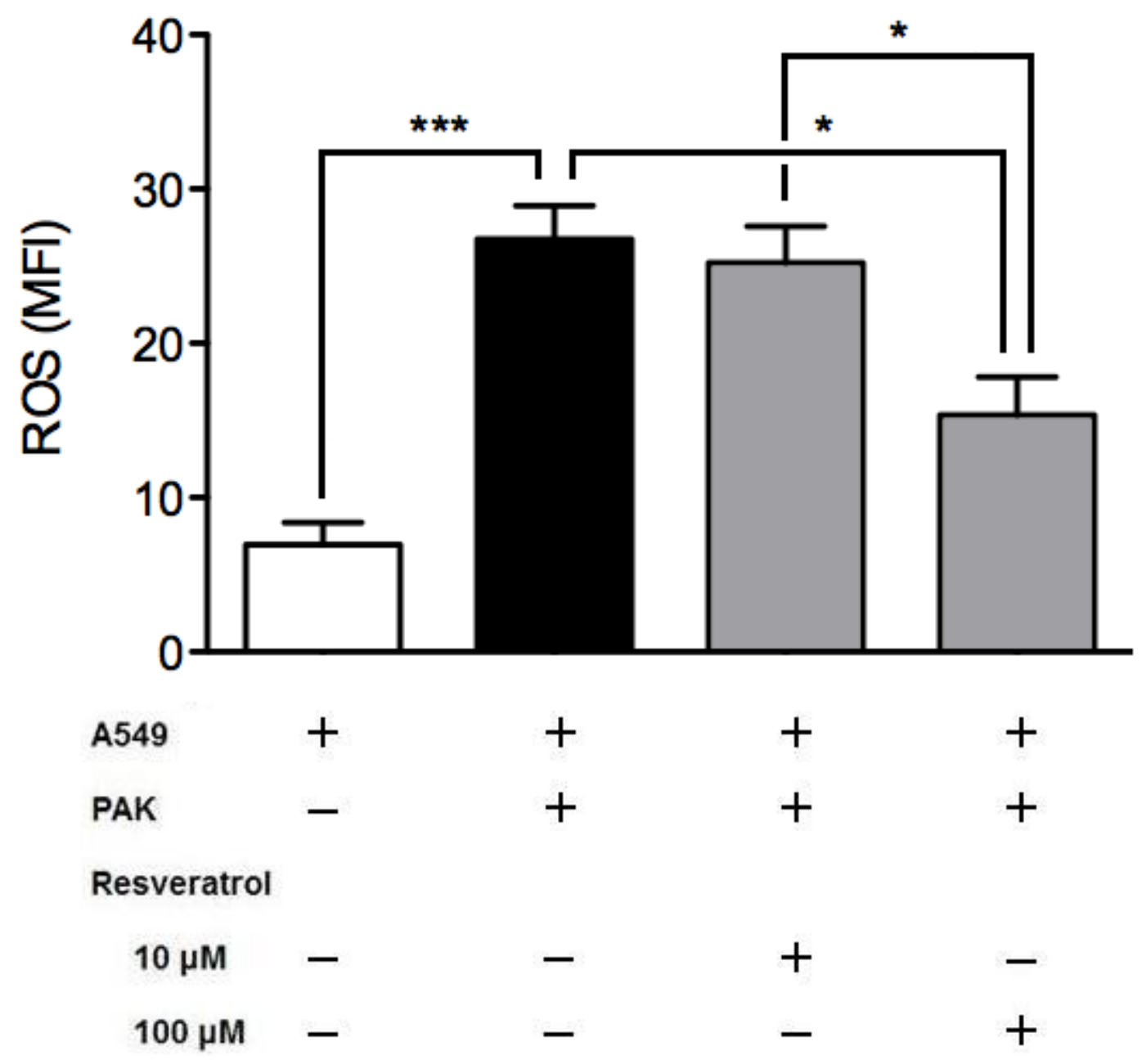

Figure 6. Effect of resveratrol on intracellular ROS levels in A549 cells infected with P. aeruginosa. Intracellular ROS levels in A549 cells were assessed using the CM$\mathrm{H}_{2}$ DCFDA assay. Cells were seeded onto 6-well plates, grown overnight to $\sim 80 \%$ confluence, and pre-treated with 10 or $100 \mu \mathrm{M}$ resveratrol in serum-free media for 4 hours followed by infection with $P$. aeruginosa MOI 50:1 for 1 hour. Cells were then incubated with the fluorescent label for 30 minutes, and a minimum of $1 \times 10^{4}$ gated events, as determined using forward and side scatter properties, were analyzed via flow cytometry (FL-1 Channel). Bars represent mean \pm SEM of 3 independent experiments. $(* p<0.05, * * * p<0.001 ;$ MFI, mean fluorescence intensity) 


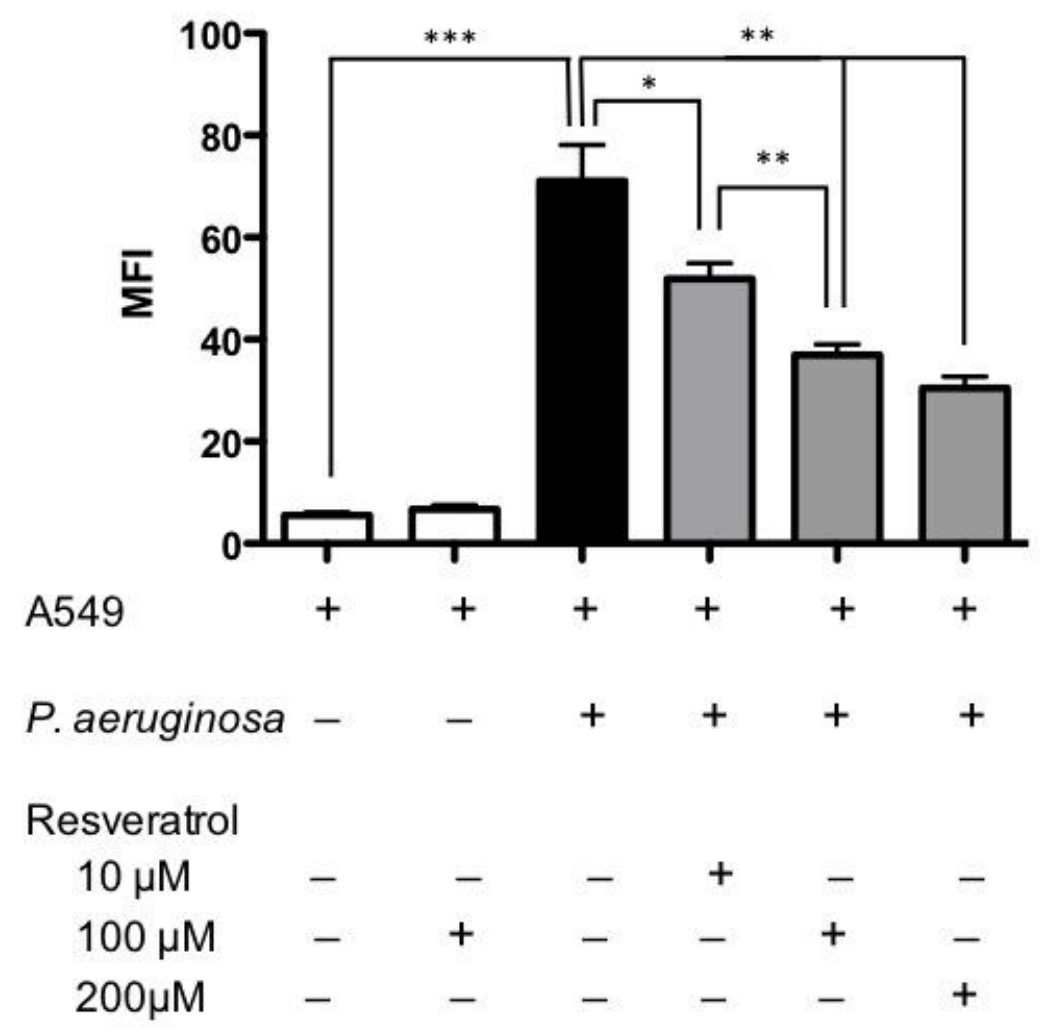

Figure 7. Effect of resveratrol pre-treatment on intracellular levels of bacteriainduced ROS. Intracellular ROS levels in A549 cells were assessed using the CM$\mathrm{H}_{2}$ DCFDA assay. Cells were seeded onto 6-well plates, grown overnight to $\sim 80 \%$ confluence, and pre-treated with 10,100 , or $200 \mu \mathrm{M}$ resveratrol in serum-free media for 5 hours followed by infection with $P$. aeruginosa MOI 100:1 for 1 hour. Cells were then incubated with the fluorescent label for 30 minutes, and a minimum of $1 \times 10^{4}$ gated events were analyzed via flow cytometry (FL-1 Channel). Bars represent mean \pm SEM of 3 independent experiments. $\left(^{*} p<0.05, * * p<0.01\right.$, *** $p<0.001$; MFI, mean fluorescence intensity) 


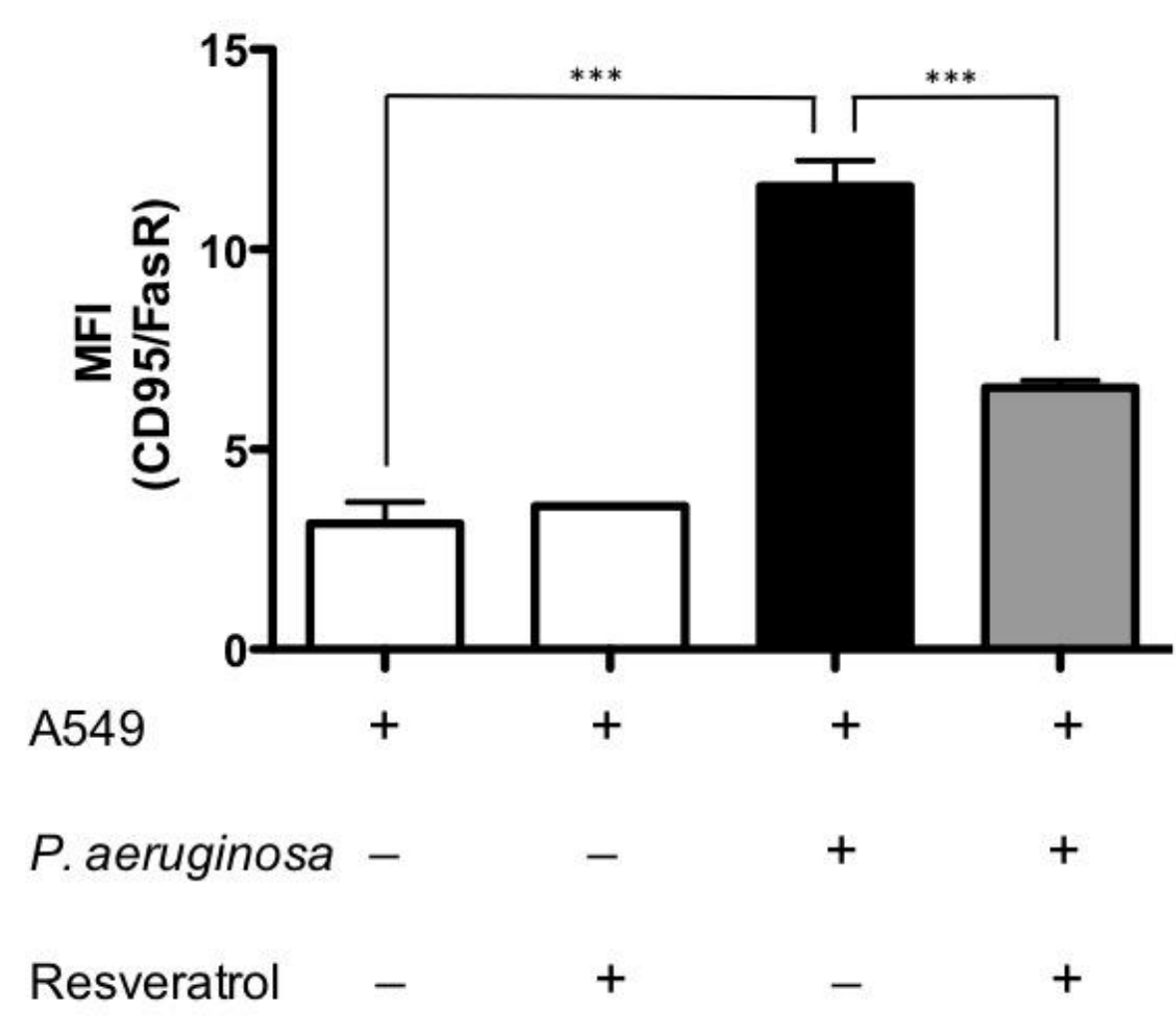

Figure 8. Effect of resveratrol on FasR/CD95 expression. Analysis of cell surface expression of Fas/CD95 was assessed via immunostaining with fluorescein isothiocyanate-conjugated mAb to CD95 (DX2) and analyzed via flow cytometry. A549 cells were seeded onto $\mathrm{T}-25 \mathrm{~cm}^{2}$ flasks for 48 hours to $\sim 80 \%$ confluence, and incubated in serum-free media in the presence of $100 \mu \mathrm{M}$ resveratrol for 5 hours, followed by a 1 hour infection with $P$. aeruginosa MOI 50:1 and a 17 hour co-incubation with $50 \mathrm{mg} / \mathrm{mL}$ polymyxin B. Cells were then immunostained with antibodies against CD95 and a minimum of $1 \times 10^{4}$ gated events were analyzed via flow cytometry (FL-1 Channel). Bars represent mean \pm SEM of 3 independent experiments. (*** $p<0.001$; FasR, Fas receptor; MFI, mean fluorescence intensity). 


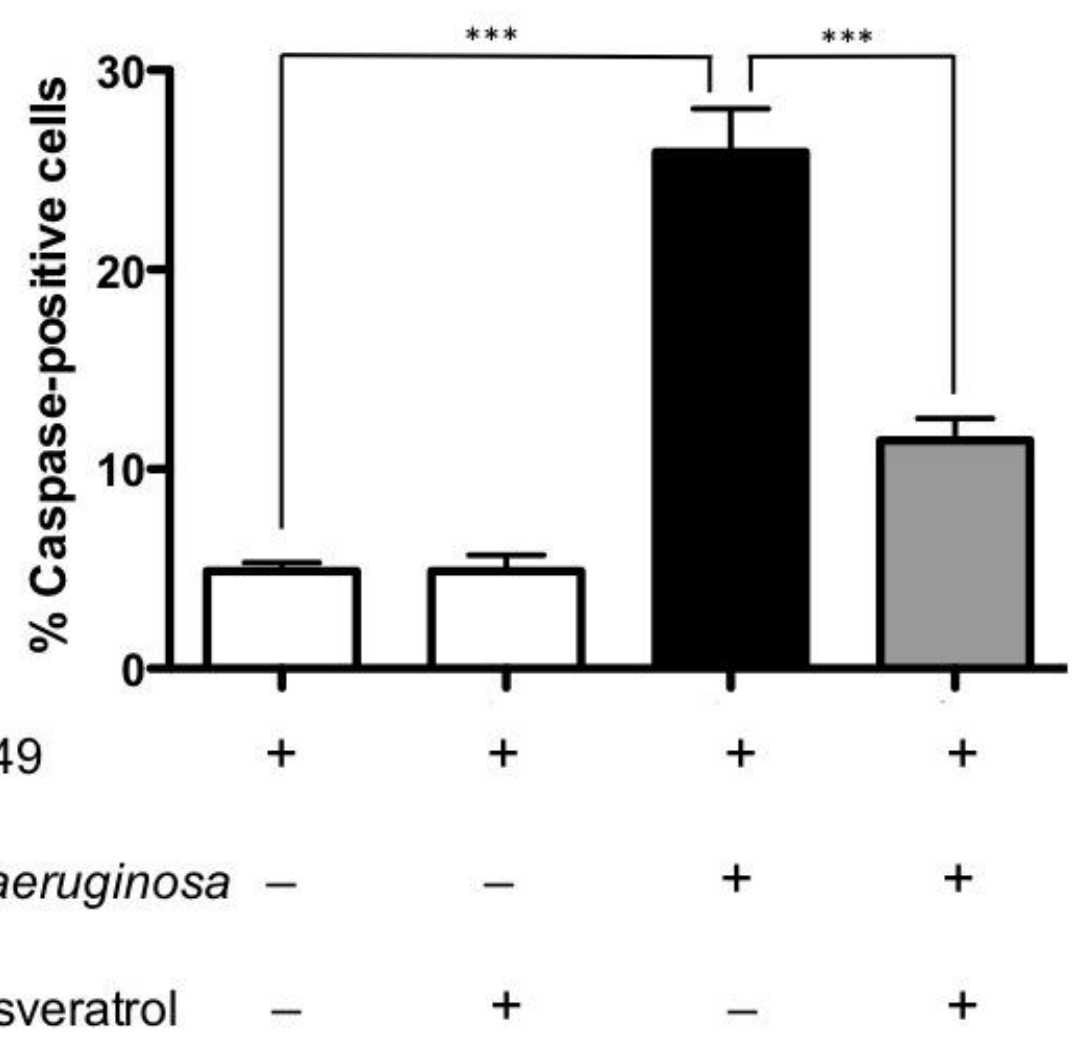

Figure 9. Effect of resveratrol on $\boldsymbol{P}$. aeruginosa-induced apoptosis. The effect of resveratrol on apoptosis in A549 cells infected with P. aeruginosa was assessed via fluorescent detection of active caspases-3 and -7 (CaspaTag Caspase 3,7 In Situ Assay Kit). Cells were seeded onto $\mathrm{T}-25 \mathrm{~cm}^{2}$ flasks for 48 hours to $\sim 80 \%$ confluence, and incubated in serum-free media in the presence of $100 \mu \mathrm{M}$ resveratrol for 5 hours followed by infection with $P$. aeruginosa MOI 50:1 in serum-free media for 2 hours. Cells were incubated with fluorescent inhibitors of caspases (FLICA) for 1 hour, and a minimum of $1 \times 10^{4}$ gated events were analyzed via flow cytometry (FL-1 Channel). Bars represent mean \pm SEM of 3 independent experiments. $(* * * p<0.001)$. 


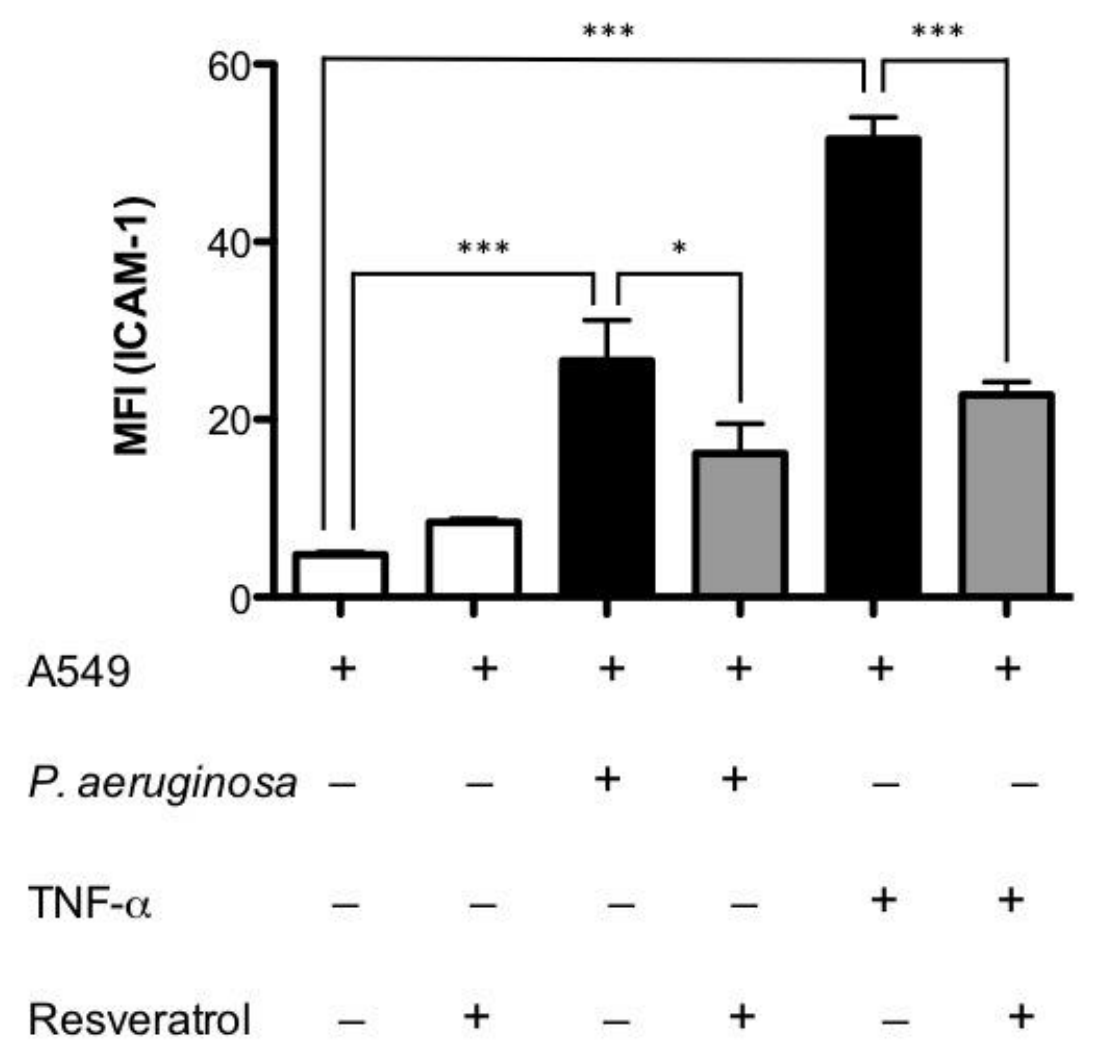

Figure 10. Effect of resveratrol on ICAM-1 expression. Analysis of cell surface expression of ICAM-1 was assessed via immunostaining with phycoerythrin-conjugated mAb to ICAM-1 (HA58) and analyzed via flow cytometry. A549 cells were seeded onto $\mathrm{T}-25 \mathrm{~cm}^{2}$ flasks for 48 hours to $\sim 80 \%$ confluence, and incubated in serum-free media in the presence of $100 \mu \mathrm{M}$ resveratrol for 5 hours, followed by either an 18 hour stimulation with $10 \mathrm{ng} / \mathrm{mL}$ TNF- $\alpha$ or 1 hour infection with $P$. aeruginosa MOI 50:1 and a 17 hour co-incubation with $50 \mathrm{mg} / \mathrm{mL}$ polymyxin B. Cells were then incubated with antibodies against ICAM-1 and a minimum of $1 \times 10^{4}$ gated events were analyzed via flow cytometry (FL-2 Channel). Bars represent mean \pm SEM of 3 independent experiments. $\left({ }^{*} p<0.05, * * * p<0.001 ; \mathrm{MFI}\right.$, mean fluorescence intensity) 


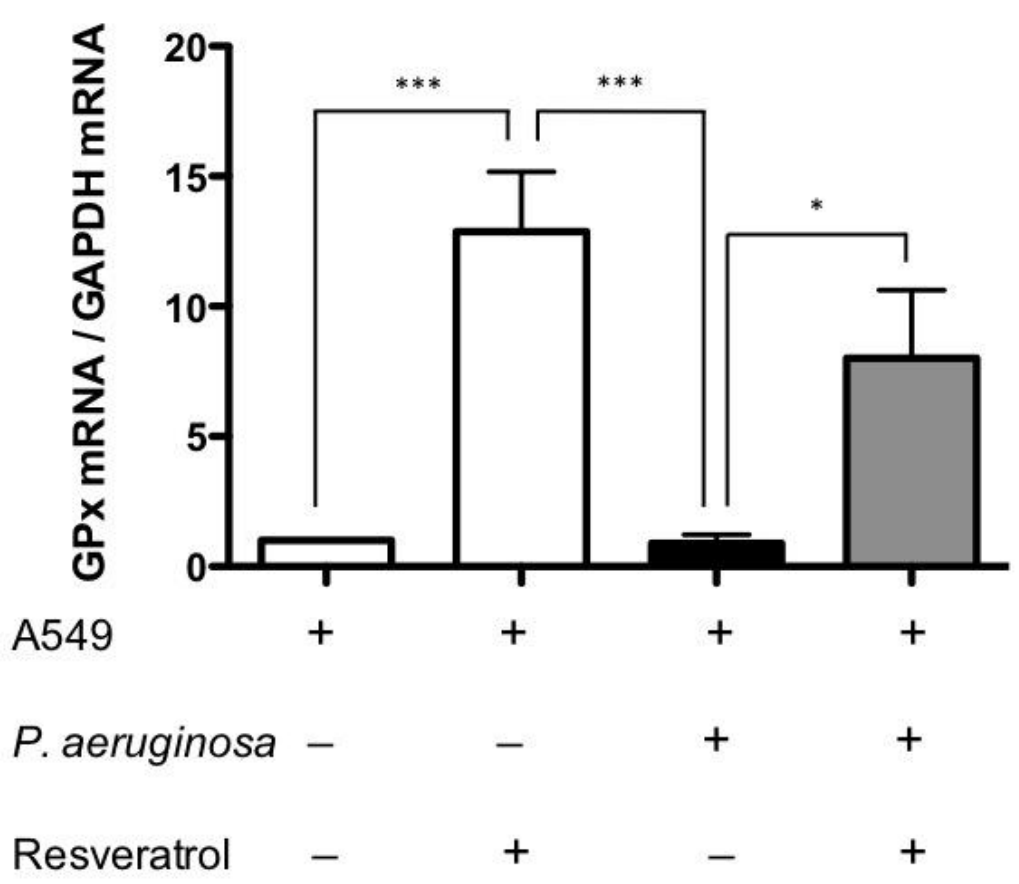

Figure 11. Effect of resveratrol on GPx mRNA expression in A549 cells infected with $P$. aeruginosa. The effect of resveratrol on GPx mRNA expression in A549 cells infected with $P$. aeruginosa was assessed via qPCR. A549 cells were seeded onto T-25 $\mathrm{cm}^{2}$ tissue culture flasks, grown for 48 hours to $\sim 80 \%$ confluency, and incubated in serum-free medium in the presence of $100 \mu \mathrm{M}$ resveratrol for 5 hours, followed by infection with $P$. aeruginosa MOI 50:1 in serum-free media for 3 hours. Cells were lysed and their RNA was isolated via silica membrane spin column. RNA quantity and integrity was assessed via automated electrophoresis. cDNA was generated via oligo-dT-primed reverse transcription. Real-time PCR was performed via a two-step cycling program in accordance with the DNA polymerase and primer specifications. Results were normalized to GAPDH. Bars represent mean \pm SEM of 3 independent experiments. $(* p<0.05, * * * p<0.001 ;$ MOI, multiplicity of infection; qPCR, quantitative PCR) 


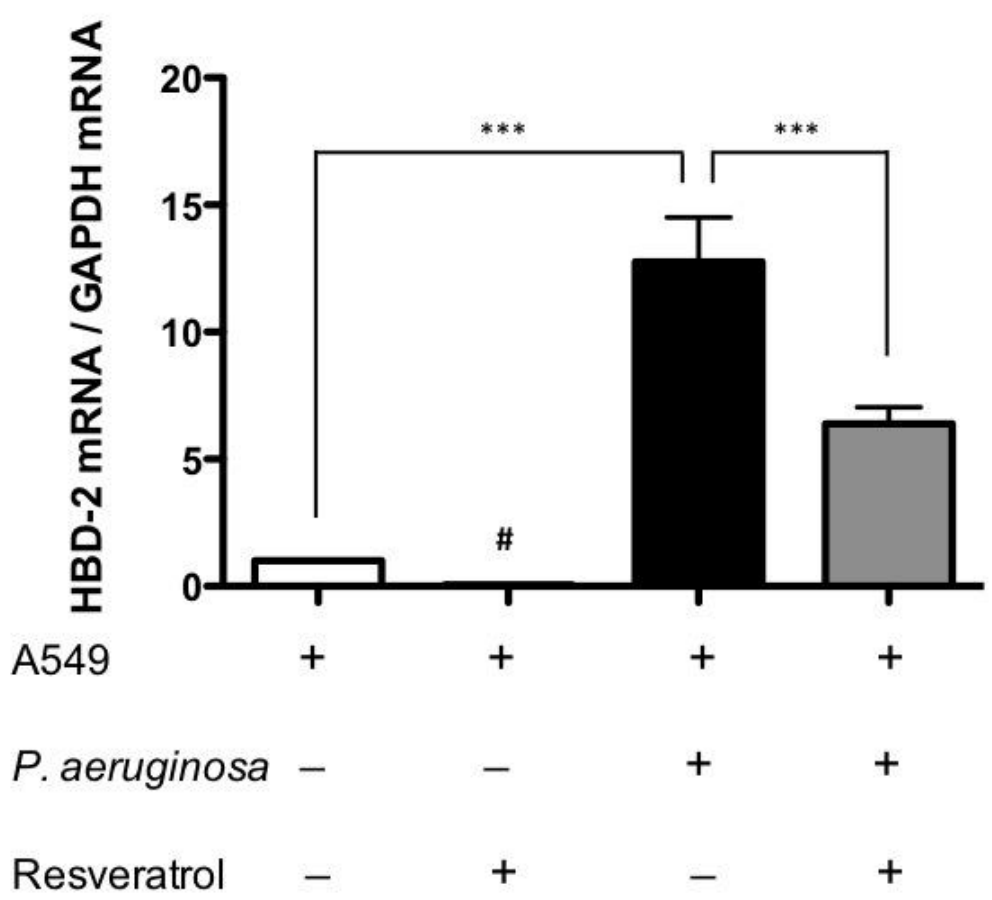

Figure 12. Effect of resveratrol on HBD-2 mRNA expression in A549 cells infected with $\boldsymbol{P}$. aeruginosa. The effect of resveratrol on HBD-2 mRNA expression in A549 cells infected with P. aeruginosa was assessed via qPCR. A549 cells were seeded onto T-25 $\mathrm{cm}^{2}$ tissue culture flasks, grown for 48 hours to $\sim 80 \%$ confluency, and incubated in serum-free medium in the presence of $100 \mu \mathrm{M}$ resveratrol for 5 hours, followed by infection with $P$. aeruginosa MOI 50:1 in serum-free media for 3 hours. Cells were lysed and RNA was isolated via silica membrane spin column. RNA quantity and integrity was assessed via automated electrophoresis. cDNA was generated via oligo-dT-primed reverse transcription. Real-time PCR was performed via a two-step cycling program in accordance with the DNA polymerase and primer specifications. Results were normalized to GAPDH. Bars represent mean \pm SEM of 3 independent experiments. (*** $p<0.001$; \# resveratrol control $=0.05430 \pm 0.001577$; MOI, multiplicity of infection; qPCR, quantitative PCR) 


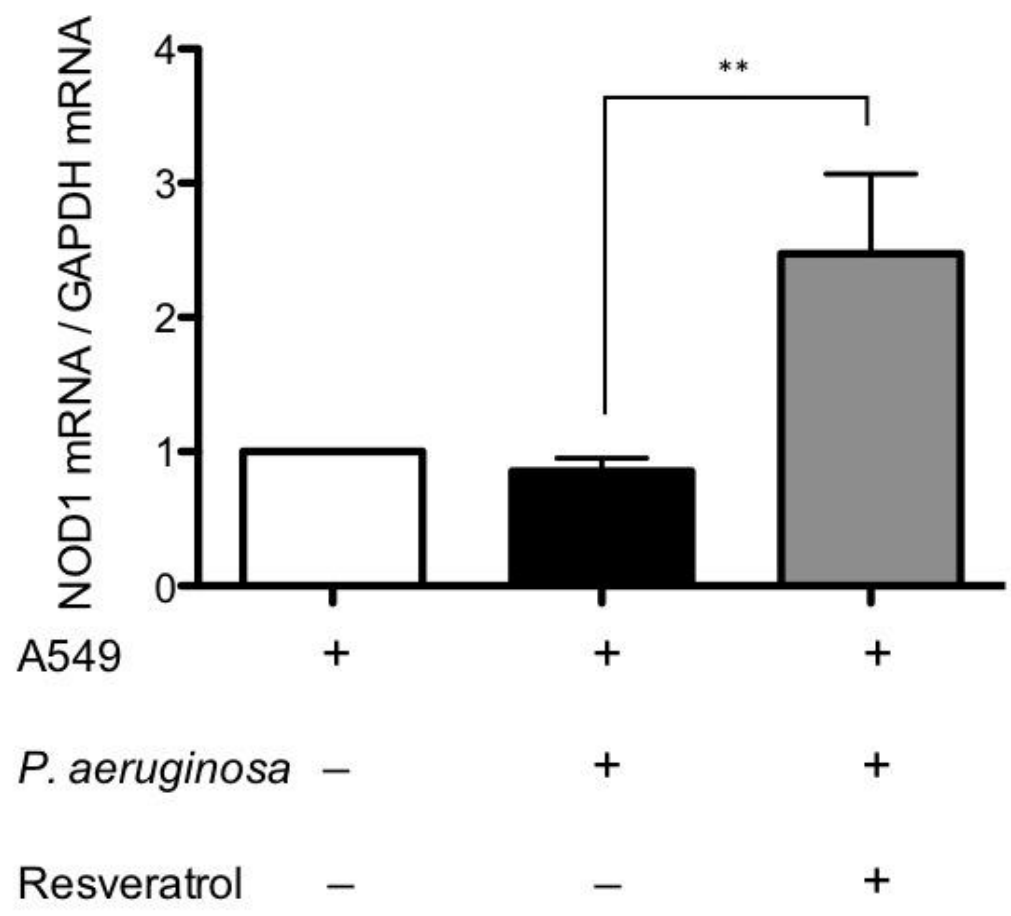

Figure 13. Effect of resveratrol on Nod1 mRNA expression in A549 cells infected with $\boldsymbol{P}$. aeruginosa. The effect of resveratrol on Nod1 mRNA expression in A549 cells infected with $P$. aeruginosa was assessed via qPCR. A549 cells were seeded onto T-25 $\mathrm{cm}^{2}$ tissue culture flasks, grown for 48 hours to $\sim 80 \%$ confluency, and incubated in serum- and antibiotic-free medium in the presence of $100 \mu \mathrm{M}$ resveratrol for 5 hours, followed by infection with $P$. aeruginosa MOI 50:1 in serum-free media for 3 hours. Cells were lysed and their RNA was isolated via silica membrane spin column. RNA quantity and integrity was assessed via automated electrophoresis. cDNA was generated via oligo-dT-primed reverse transcription. Real-time PCR was performed via a two-step cycling program in accordance with the DNA polymerase and primer specifications. Results were normalized to GAPDH. Bars represent mean \pm SEM of 3 independent experiments. (** $p<0.01$; MOI, multiplicity of infection; qPCR, quantitative PCR) 


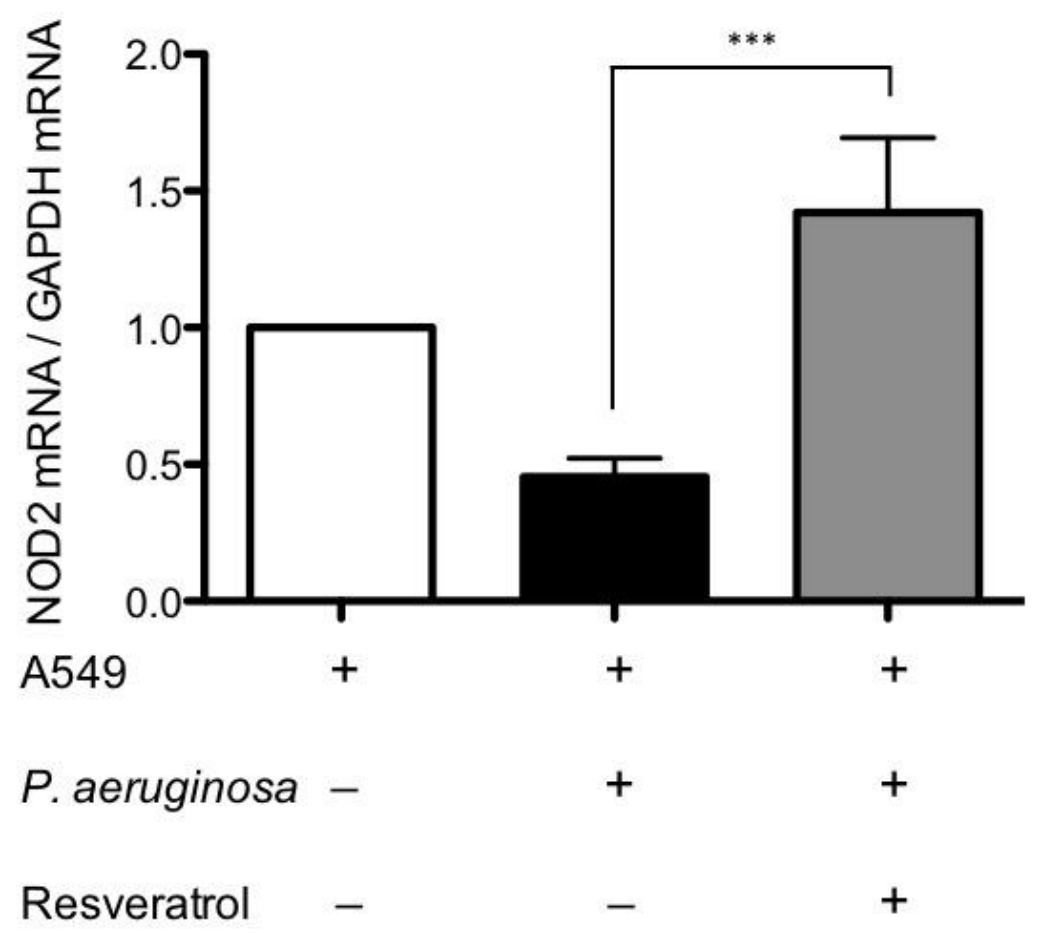

Figure 14. Effect of resveratrol on Nod2 mRNA expression in A549 cells infected with $\boldsymbol{P}$. aeruginosa. The effect of resveratrol on Nod2 mRNA expression in A549 cells infected with $P$. aeruginosa was assessed via qPCR. A549 cells were seeded onto T-25 $\mathrm{cm}^{2}$ tissue culture flasks, grown for 48 hours to $\sim 80 \%$ confluency, and incubated in serum- and antibiotic-free medium in the presence of $100 \mu \mathrm{M}$ resveratrol for 5 hours, followed by infection with $P$. aeruginosa MOI 50:1 in serum-free media for 3 hours. Cells were lysed and their RNA was isolated via silica membrane spin column. RNA quantity and integrity was assessed via automated electrophoresis. cDNA was generated via oligo-dT-primed reverse transcription. Real-time PCR was performed via a two-step cycling program in accordance with the DNA polymerase and primer specifications. Results were normalized to GAPDH. Bars represent mean \pm SEM of 3 independent experiments. $\left({ }^{* * *} p<0.001\right.$; MOI, multiplicity of infection; qPCR, quantitative PCR) 


\section{5 - Discussion}

Respiratory tract infections caused by $P$. aeruginosa provoke a robust inflammatory response in the lung leading to severe tissue damage. Many of these cellular responses are the result of important pathogen-host interactions, which when triggered, signal the activation of pro-inflammatory transcription factors (i.e. NF- $\kappa \mathrm{B}$ and AP-1) that in turn initiate the transcription and release of pro-inflammatory mediators. As a consequence, activated immune cells swarm the inflamed tissue and release proteases, myeloperoxidase, and reactive oxygen species leading to oxidative stress and contributing to lung parenchymal tissue damage seen in CF (Doring et al. 1986; Hull et al. 1997), COPD (Murphy et al. 2008; Stockley 2002), and acute lung injury (Chabot et al. 1998). It is not surprising then that a great focus has been placed on understanding the underlying mechanisms between oxidative stress and inflammation.

Resveratrol, an antioxidant compound currently believed to be at least partly responsible for the beneficial properties attributed to red wine, has been shown to exert anti-inflammatory properties in a variety of in vitro and in vivo models. To our knowledge, however, the protective effect of resveratrol in a model of $P$. aeruginosa lung infection has never been addressed. Therefore, in this study, we examined whether lung epithelial cellular responses induced by interactions with $P$. aeruginosa could be mitigated or even prevented with resveratrol pre-treatment in vitro. Indeed, we observed that infection of A549 lung adenocarcinoma cells with $P$. aeruginosa led to an upregulation of intracellular ROS production. Several virulence factors are believed to contribute to this, including the redox-active compound pyocyanin (Lau et al. 2004; Schwarzer et al. 2008) and the exotoxin (Exo)U (Saliba et al. 2006), as well as pili, LPS, and flagella, which are known to be critical inducers of inflammation (Feldman et al. 
1998; Pier 2007; Saiman et al. 1993). We have also found that pre-treatment with resveratrol successfully decreased ROS production. Interestingly, we also found that the presence of serum inhibited the antioxidant effect of resveratrol. This is likely due to the binding of resveratrol to some serum proteins. In agreement with our findings, resveratrol can be bound by protein carriers in the blood and transported in the circulation to its target tissue where it can then exert its biological effect (Jannin et al. 2004; Lancon et al. 2004).

ROS has been shown to play a critical role in the regulation of apoptosis (Simon et al. 2000), as have pro-inflammatory cytokines including TNF- $\alpha$ and IL-1 (Manna et al. 2000; Rath et al. 1999; Shakibaei et al. 2005).In the case of $P$. aeruginosa infection, airway epithelial cells undergo apoptosis via both death-receptor associated (extrinsic) and mitochondrial (extrinsic) pathways (Grassme et al. 2000; Jendrossek et al. 2001). By detecting expression levels of the death receptor Fas/CD95, involved in the extrinsic pathway, and the detection of active executioner caspases-3 and -7 , involved in both pathways, we found that $P$. aeruginosa induced apoptosis in infected cells, and that pretreatment with resveratrol decreased both markers of apoptosis post-infection. The antiapoptotic effect may be due to up-regulation of pro-survival Bcl-2 family members (Shakibaei et al. 2008), and a decrease in nuclear translocation of NF-kB as a result of inhibited IkBa degradation and p65 activity (Csaki et al. 2009). These reports are in stark contrast to several studies that have found resveratrol to be an inducer of both caspase-3/7 activation (Dorrie et al. 2001), and Fas ligand/CD95L pathway activation (Clement et al. 1998; Ko et al. 2011; Tsan et al. 2000). However, these studies used longer resveratrol pre-treatment times and different models including acute lymphoblastic leukemia cells, 
breast carcinoma cells, human monocytes, and anaplastic large-cell lymphoma cells, respectively.

Indeed, the intrinsic apoptosis pathway involves ROS-induced depolarization of the mitochondria followed by the release of cytochrome $c$ (Alaoui-El-Azher et al. 2006). In the extrinsic pathway, Fas/CD95 activation triggers aggregation the FADD adapter resulting in membrane raft clustering and receptor internalization and activation of the caspase cascade (Barnhart et al. 2003; Delmas et al. 2003; Guicciardi et al. 2009). Previous work in our lab demonstrated a significant correlation between ROS generation and active caspase-3/7 expression levels in infected A549 cells (Hawdon et al. 2010). While evidence supports the role of ROS in P. aeruginosa-induced apoptosis (Alaoui-ElAzher et al. 2006), our results suggest a protective role of resveratrol in cell death.

Acute lung infection caused by $P$. aeruginosa causes a rapid and severe inflammatory response characterized by increased surface expression of the cell-surface adhesion molecule ICAM-1, which is critical in the recruitment of inflammatory cells to the infected tissue, and pro-inflammatory mediator release (i.e. cytokines and antimicrobial peptides) (Harder et al. 2000; Sadikot et al. 2005; Wehkamp et al. 2006). Thus, we chose to examine the effect of resveratrol on inflammation caused by $P$. aeruginosa infection by measuring ICAM-1 and human beta-defensin-2 (HBD-2) expression. In agreement with the literature, we found that both ICAM-1 (Aldallal et al. 2002) and HBD-2 (Harder et al. 2000; Wehkamp et al. 2006) expression were induced by P. aeruginosa in A549 cells. Studies with resveratrol demonstrated a decrease in both ICAM-1 and HBD-2, confirming that resveratrol possesses anti-inflammatory properties in our model of acute lung infection. 
Indeed, promoter regions for the antimicrobial peptide, HBD-2, have been found to contain binding sites for pro-inflammatory transcription factors, including NF- $\mathrm{kB}$ and AP-1(Harder et al. 2000). As a part of the innate immune response, HBD-2 is released by airway epithelial cells infected with $P$. aeruginosa, and works on either epithelial cell surfaces or synergistically within phagocyte phagolysosomes to kill bacteria (Harder et al. 2000; Schroder et al. 1999). Despite the inflammatory properties of HBD-2, antimicrobial peptide suppression may increase the likelihood of sustained infection (Schroder et al. 1999). Thus, in relation to our findings, we suggest here that resveratrol may decrease the innate immune response to $P$. aeruginosa infection.

Nod proteins (nucleotide binding, oligomerization domains) act as intracellular sentinels of bacterial products and can activate NF- $\mathrm{KB}$ directly (Martin et al. 2005). While Nod1 is ubiquitously expressed and recognizes muramyl tripeptides in the cell walls of Gram-negative bacteria, Nod2 expression is more cell-type specific and recognizes muramyl dipeptides found in both Gram-positive and Gram-negative bacterial cell walls (Franchi et al. 2008). In our experiments, however, P. aeruginosa had no effect on Nod1 or Nod2 gene expression levels, however pre-treatment with resveratrol caused an increase in these receptors. Further study is needed to clarify the effect of antioxidants, like resveratrol, on NLRs.

Emerging evidence implicates resveratrol as an inducer of antioxidant enzymes, conferring mostly indirect cellular protection against oxidative stress (Hu et al. 2007; Kode et al. 2008; Robb et al. 2008). Currently, studies by others suggest that resveratrol can up-regulate levels of catalase, thioredoxin, thioredoxin reductase, and mitochondrial superoxide dismutase (MnSOD), as well as glutathione (GSH) and glutathione 
peroxidase (GPx) (Hu et al. 2007; Kode et al. 2008; Robb et al. 2008; Ungvari et al. 2007). Indeed, GSH is widely considered the master antioxidant of the cell and works in concert with GPx to convert lipid peroxides, $\mathrm{H}_{2} \mathrm{O}_{2}$, and other radicals into less toxic forms (Rahman et al. 2000). In our results, expression levels of GPx in A549 cells infected with $P$. aeruginosa remained unchanged compared to control. Resveratrol pretreatment, however, initiated a sharp increase in GPx mRNA expression correlating with the previously mentioned studies. This is interesting because expression of the death receptor Fas/CD95 is regulated by intracellular GSH levels (Chiba et al. 1996), and Fas/CD95 has been found to decrease cellular GSH levels (van den Dobbelsteen et al. 1996). These studies also suggest that resveratrol can exert beneficial antioxidant effects earlier than $18-24$ hours as previously reported (Donnelly et al. 2004; Kode et al. 2008; Ungvari et al. 2007).

Our study is limited, however, by the scope of our model. First and foremost, one must be careful in interpreting data from an in vitro model, as in vivo there are many more cell types involved in the pathophysiology of lung inflammation and bacterial infection. As well, while the signaling pathways explored in our model (i.e. apoptosis and inflammation) may be activated independently, their signaling pathways are not mutually exclusive, and can often feedback into each other. Moreover, P. aeruginosa infection may activate inflammatory pathways in microenvironments not yet experiencing oxidative stress. It is this convergence, however, which leads to a vicious cycle of tissue damage and runaway inflammation.

With this in mind there are still many avenues of study needed to expand the ideas presented here. An important question left unaddressed is the direct effect of resveratrol 
on $P$. aeruginosa viability. As a phytoalexin, resveratrol can be produced in several plant species as a part of a defensive strategy during bacterial or fungal attack (Donnelly et al. 2004), and while it was reported that resveratrol (ranging at concentrations of 171-342 $\mu \mathrm{g} / \mathrm{ml}$ ) inhibited the growth of Enterococcus faecalis, Staphylococcus aeurus, Pseudomonas aeruginosa, and several dermatophyte species (Chan 2002), it remains to be seen if and/or how resveratrol retains these microbicidal effects in the in vitro and in vivo settings. An interesting way to measure this with respect to our model would be to determine the effect of resveratrol on the internalization of $P$. aeruginosa into the lung epithelial cell. Alive or not, $P$. aeruginosa virulence factors may still initiate inflammatory responses mediated through TLR-activation (Sadikot et al. 2005), thus in terms of our findings it is unlikely that resveratrol exerts its anti-inflammatory effects via only antibacterial means.

To confirm the anti-apoptotic properties of resveratrol it would be helpful to measure any changes in mitochondrial membrane potential. As well, measuring levels of active caspase-9 would help clarify the mechanism used by resveratrol to prevent cell death. Continuing downstream, measuring the direct activation of both NF-kB and AP-1 would also be pivotal markers in confirming the effect of resveratrol in this model. Lastly, while the use of immortalized cell lines like A549 are both invaluable and practical, a natural improvement would be to test the anti-inflammatory and antioxidative effects of resveratrol in primary human lung epithelial cells. Such studies would help pave the way for clearer clinical interpretations. 


\section{6 - Conclusion}

To summarize, we have established that the antioxidant resveratrol can protect against pathogen-induced potentially damaging cellular responses during infection of type II lung epithelial A549 cells with $P$. aeruginosa in vitro by unburdening the cell from oxidative stress, decreasing inflammatory responses implicated in tissue damage, and possibly influencing innate immune responses. Despite intense focus on the putative mechanisms underlying the diverse activities of resveratrol in different tissues, contradictory results emerge, making complete understanding of underlying mechanisms difficult. Regardless, understanding the preventative and therapeutic relationships between natural antioxidants and bacterial-induced inflammation remains a worthwhile endeavor. 


\section{8 - References}

Alaoui-El-Azher, et al. 2006. ExoS of Pseudomonas aeruginosa induces apoptosis through a Fas receptor/caspase 8-independent pathway in HeLa cells. Cell Microbiol, 8(2), 326-338.

Alarcon de la Lastra, \& Villegas. 2007. Resveratrol as an antioxidant and pro-oxidant agent: mechanisms and clinical implications. Biochem Soc Trans, 35(Pt 5), 1156-1160.

Aldallal, et al. 2002. Inflammatory response in airway epithelial cells isolated from patients with cystic fibrosis. Am J Respir Crit Care Med, 166(9), 1248-1256.

Asensi, et al. 2002. Inhibition of cancer growth by resveratrol is related to its low bioavailability. Free Radic Biol Med, 33(3), 387-398.

Barnhart, et al. 2003. The CD95 type I/type II model. Semin Immunol, 15(3), 185-193.

Baur, \& Sinclair. 2006. Therapeutic potential of resveratrol: the in vivo evidence. Nat Rev Drug Discov, 5(6), 493-506.

Bertelli, et al. 2001. Resveratrol inhibits TNF alpha-induced endothelial cell activation. Therapie, 56(5), 613-616. 
Bianchi, et al. 2008. Impairment of apoptotic cell engulfment by pyocyanin, a toxic metabolite of Pseudomonas aeruginosa. Am J Respir Crit Care Med, 177(1), 35-43.

Bilska, \& Wlodek. 2005. Lipoic acid - the drug of the future? Pharmacol Rep, 57(5), 570577.

Bonten, et al. 1999. Characteristics of polyclonal endemicity of Pseudomonas aeruginosa colonization in intensive care units. Implications for infection control. Am J Respir Crit Care Med, 160(4), 1212-1219.

Cavallaro, et al. 2003. Effect of resveratrol on some activities of isolated and in whole blood human neutrophils. Physiol Res, 52(5), 555-562.

Chabot, et al. 1998. Reactive oxygen species in acute lung injury. Eur Respir J, 11(3), $745-757$.

Chan. 2002. Antimicrobial effect of resveratrol on dermatophytes and bacterial pathogens of the skin. Biochem Pharmacol, 63(2), 99-104.

Chastre, \& Fagon. 2002. Ventilator-associated pneumonia. Am J Respir Crit Care Med, 165(7), 867-903.

Chiba, et al. 1996. Fas-mediated apoptosis is modulated by intracellular glutathione in human T cells. Eur J Immunol, 26(5), 1164-1169. 
Chow, et al. 2003. Oxidative stress and acute lung injury. Am J Respir Cell Mol Biol, 29(4), 427-431.

Ciencewicki, et al. 2008. Oxidants and the pathogenesis of lung diseases. J Allergy Clin Immunol, 122(3), 456-468; quiz 469-470.

Ciofu, et al. 2005. Occurrence of hypermutable Pseudomonas aeruginosa in cystic fibrosis patients is associated with the oxidative stress caused by chronic lung inflammation. Antimicrob Agents Chemother, 49(6), 2276-2282.

Clement, et al. 1998. Chemopreventive agent resveratrol, a natural product derived from grapes, triggers CD95 signaling-dependent apoptosis in human tumor cells. Blood, 92(3), 996-1002.

Creasy. 1988. Phytoalexin production potential of grape berries. Journal of the American Society for Horticultural Science, 113(230-234).

Crouch Brewer, et al. 1996. Ventilator-associated pneumonia due to Pseudomonas aeruginosa. Chest, 109(4), 1019-1029.

Csaki, et al. 2009. Synergistic chondroprotective effects of curcumin and resveratrol in human articular chondrocytes: inhibition of IL-1 beta-induced NF-kappaB-mediated inflammation and apoptosis. Arthritis Res Ther, 11(6), R165. 
Daniel, et al. 1999. Selected phenolic compounds in cultivated plants: ecologic functions, health implications, and modulation by pesticides. Environ Health Perspect, 107 Suppl 1, $109-114$.

Delbridge, \& O'Riordan. 2007. Innate recognition of intracellular bacteria. Curr Opin Immunol, 19(1), 10-16.

Delmas, et al. 2003. Resveratrol-induced apoptosis is associated with Fas redistribution in the rafts and the formation of a death-inducing signaling complex in colon cancer cells. $\mathrm{J}$ Biol Chem, 278(42), 41482-41490.

Deneke, \& Fanburg. 1989. Regulation of cellular glutathione. Am J Physiol, 257(4 Pt 1), L163-173.

Diamond, et al. 2000. Transcriptional regulation of beta-defensin gene expression in tracheal epithelial cells. Infect Immun, 68(1), 113-119.

Diekema, et al. 1999. Survey of bloodstream infections due to gram-negative bacilli: frequency of occurrence and antimicrobial susceptibility of isolates collected in the United States, Canada, and Latin America for the SENTRY Antimicrobial Surveillance Program, 1997. Clin Infect Dis, 29(3), 595-607.

Dinis-Oliveira, et al. 2008. Paraquat poisonings: mechanisms of lung toxicity, clinical features, and treatment. Crit Rev Toxicol, 38(1), 13-71. 
Donnelly, et al. 2004. Anti-inflammatory effects of resveratrol in lung epithelial cells: molecular mechanisms. Am J Physiol Lung Cell Mol Physiol, 287(4), L774-783.

Doring, et al. 1986. Elastase from polymorphonuclear leucocytes: a regulatory enzyme in immune complex disease. Clin Exp Immunol, 64(3), 597-605.

Dorrie, et al. 2001. Resveratrol induces extensive apoptosis by depolarizing mitochondrial membranes and activating caspase-9 in acute lymphoblastic leukemia cells. Cancer Res, 61(12), 4731-4739.

Droge, et al. 1994. Functions of glutathione and glutathione disulfide in immunology and immunopathology. FASEB J, 8(14), 1131-1138.

Durand, et al. 2003. Type II protein secretion in Pseudomonas aeruginosa: the pseudopilus is a multifibrillar and adhesive structure. J Bacteriol, 185(9), 2749-2758.

Dustin, \& Springer. 1988. Lymphocyte function-associated antigen-1 (LFA-1) interaction with intercellular adhesion molecule-1 (ICAM-1) is one of at least three mechanisms for lymphocyte adhesion to cultured endothelial cells. J Cell Biol, 107(1), 321-331.

Engel, \& Balachandran. 2009. Role of Pseudomonas aeruginosa type III effectors in disease. Curr Opin Microbiol, 12(1), 61-66. 
Ernst, et al. 2003. Pseudomonas aeruginosa lipid A diversity and its recognition by Tolllike receptor 4. J Endotoxin Res, 9(6), 395-400.

Evans, et al. 2010. Inducible innate resistance of lung epithelium to infection. Annu Rev Physiol, 72, 413-435.

Feldman, et al. 1998. Role of flagella in pathogenesis of Pseudomonas aeruginosa pulmonary infection. Infect Immun, 66(1), 43-51.

Ferrero, et al. 1998. Activity in vitro of resveratrol on granulocyte and monocyte adhesion to endothelium. Am J Clin Nutr, 68(6), 1208-1214.

Franchi, et al. 2008. Intracellular NOD-like receptors in innate immunity, infection and disease. Cell Microbiol, 10(1), 1-8.

Fremont. 2000. Biological effects of resveratrol. Life Sci, 66(8), 663-673.

Fulgenzi, et al. 2001. In vivo inhibition of TNFalpha-induced vascular permeability by resveratrol. Transplant Proc, 33(3), 2341-2343.

Geddes, et al. 2009. Unleashing the therapeutic potential of NOD-like receptors. Nat Rev Drug Discov, 8(6), 465-479.

Girardin, et al. 2003. Nod1 detects a unique muropeptide from gram-negative bacterial peptidoglycan. Science, 300(5625), 1584-1587. 
Goldberg. 1995. Does wine work? Clin Chem, 41(1), 14-16.

Gram. 1997. Chemically reactive intermediates and pulmonary xenobiotic toxicity. Pharmacol Rev, 49(4), 297-341.

Grassme, et al. 2000. CD95/CD95 ligand interactions on epithelial cells in host defense to Pseudomonas aeruginosa. Science, 290(5491), 527-530.

Guicciardi, \& Gores. 2009. Life and death by death receptors. FASEB J, 23(6), 16251637.

Haddad. 2004. Redox and oxidant-mediated regulation of apoptosis signaling pathways: immuno-pharmaco-redox conception of oxidative siege versus cell death commitment. Int Immunopharmacol, 4(4), 475-493.

Hao, \& He. 2004. Mechanisms of cardiovascular protection by resveratrol. J Med Food, 7(3), 290-298.

Harder, et al. 2000. Mucoid Pseudomonas aeruginosa, TNF-alpha, and IL-1beta, but not IL-6, induce human beta-defensin-2 in respiratory epithelia. Am J Respir Cell Mol Biol, 22(6), 714-721. 
Hawdon, et al. 2010. Cellular responses of A549 alveolar epithelial cells to serially collected Pseudomonas aeruginosa from cystic fibrosis patients at different stages of pulmonary infection. FEMS Immunol Med Microbiol, 59(2), 207-220.

Hippenstiel, et al. 2006. Lung epithelium as a sentinel and effector system in pneumonia-molecular mechanisms of pathogen recognition and signal transduction. Respir Res, 7, 97.

Hogg, et al. 1991. Structure and function of intercellular adhesion molecule-1. Chem Immunol, 50, 98-115.

Holloway. 1955. Genetic recombination in Pseudomonas aeruginosa. J Gen Microbiol, 13(3), 572-581.

$\mathrm{Hu}$, et al. 2007. Resveratrol modulates mRNA transcripts of genes related to redox metabolism and cell proliferation in non-small-cell lung carcinoma cells. Biol Chem, 388(2), 207-219.

Huang, et al. 2007. In vitro activity of human beta-defensin 2 against Pseudomonas aeruginosa in the presence of tear fluid. Antimicrob Agents Chemother, 51(11), 38533860.

Hull, et al. 1997. Pulmonary oxidative stress response in young children with cystic fibrosis. Thorax, 52(6), 557-560. 
Ignatowicz, \& Baer-Dubowska. 2001. Resveratrol, a natural chemopreventive agent against degenerative diseases. Pol J Pharmacol, 53(6), 557-569.

Inohara, et al. 2005. NOD-LRR proteins: role in host-microbial interactions and inflammatory disease. Annu Rev Biochem, 74, 355-383.

Jannin, et al. 2004. Transport of resveratrol, a cancer chemopreventive agent, to cellular targets: plasmatic protein binding and cell uptake. Biochem Pharmacol, 68(6), 11131118.

Jeandet. 1991. The Production of Resveratrol (3,5,4'-trihydroxystilbene) by Grape Berries in Different Developmental Stages. American Journal of Enology and Viticulture, 42(1), 41-46.

Jendrossek, et al. 2001. Pseudomonas aeruginosa-induced apoptosis involves mitochondria and stress-activated protein kinases. Infect Immun, 69(4), 2675-2683.

Kaldas, et al. 2003. Resveratrol transport and metabolism by human intestinal Caco-2 cells. J Pharm Pharmacol, 55(3), 307-312.

Kipnis, et al. 2006. Targeting mechanisms of Pseudomonas aeruginosa pathogenesis. Med Mal Infect, 36(2), 78-91. 
Knowles, \& Boucher. 2002. Mucus clearance as a primary innate defense mechanism for mammalian airways. J Clin Invest, 109(5), 571-577.

Ko, et al. 2011. Resveratrol enhances the expression of death receptor Fas/CD95 and induces differentiation and apoptosis in anaplastic large-cell lymphoma cells. Cancer Lett, 309(1), 46-53.

Kode, et al. 2008. Resveratrol induces glutathione synthesis by activation of Nrf2 and protects against cigarette smoke-mediated oxidative stress in human lung epithelial cells. Am J Physiol Lung Cell Mol Physiol, 294(3), L478-488.

Krunkosky, et al. 2000. Effects of TNF-alpha on expression of ICAM-1 in human airway epithelial cells in vitro. Signaling pathways controlling surface and gene expression. Am J Respir Cell Mol Biol, 22(6), 685-692.

Kuribayashi, et al. 2006. What are caspases 3 and 7 doing upstream of the mitochondria? Cancer Biol Ther, 5(7), 763-765.

Lakhani, et al. 2006. Caspases 3 and 7: key mediators of mitochondrial events of apoptosis. Science, 311(5762), 847-851.

Lancon, et al. 2004. Human hepatic cell uptake of resveratrol: involvement of both passive diffusion and carrier-mediated process. Biochem Biophys Res Commun, 316(4), 1132-1137. 
Langcake. 1976. Production of resveratrol by Vitis-vinifera and other members of Vitaceae as a response to infection or injury. Physiological Plant Pathology, 9(1), 77-86.

Lau, et al. 2004. The role of pyocyanin in Pseudomonas aeruginosa infection. Trends Mol Med, 10(12), 599-606.

Leiro, et al. 2004. Effects of cis-resveratrol on inflammatory murine macrophages: antioxidant activity and down-regulation of inflammatory genes. J Leukoc Biol, 75(6), 1156-1165.

$\mathrm{Li}$, et al. 1994. An investigation of the role of glutathione in increased epithelial permeability induced by cigarette smoke in vivo and in vitro. Am J Respir Crit Care Med, 149(6), 1518-1525.

Li, et al. 1996. Mechanisms of cigarette smoke induced increased airspace permeability. Thorax, 51(5), 465-471.

Look, et al. 1992. Selective induction of intercellular adhesion molecule-1 by interferongamma in human airway epithelial cells. Am J Physiol, 263(1 Pt 1), L79-87.

Lopez-Velez, et al. 2003. The study of phenolic compounds as natural antioxidants in wine. Crit Rev Food Sci Nutr, 43(3), 233-244. 
$\mathrm{Lu}$, et al. 2009. Resveratrol-loaded polymeric micelles protect cells from Abeta-induced oxidative stress. Int J Pharm, 375(1-2), 89-96.

Mak. 2008. Pathogenesis of COPD. Part II. Oxidative-antioxidative imbalance. Int J Tuberc Lung Dis, 12(4), 368-374.

Manna, et al. 2000. Resveratrol suppresses TNF-induced activation of nuclear transcription factors NF-kappa B, activator protein-1, and apoptosis: potential role of reactive oxygen intermediates and lipid peroxidation. J Immunol, 164(12), 6509-6519.

Marier, et al. 2002. Metabolism and disposition of resveratrol in rats: extent of absorption, glucuronidation, and enterohepatic recirculation evidenced by a linked-rat model. J Pharmacol Exp Ther, 302(1), 369-373.

Martin, \& Frevert. 2005. Innate immunity in the lungs. Proc Am Thorac Soc, 2(5), 403411.

Mizuta, et al. 2008. Fas ligand released by activated monocytes causes apoptosis of lung epithelial cells in human acute lung injury model in vitro. Biol Pharm Bull, 31(3), 386390.

Murphy, et al. 2008. Pseudomonas aeruginosa in chronic obstructive pulmonary disease. Am J Respir Crit Care Med, 177(8), 853-860. 
Nseir, et al. 2002. Nosocomial tracheobronchitis in mechanically ventilated patients: incidence, aetiology and outcome. Eur Respir J, 20(6), 1483-1489.

Park, et al. 2009. Impact of oxidative stress on lung diseases. Respirology, 14(1), 27-38.

Pervaiz. 2003. Resveratrol: from grapevines to mammalian biology. FASEB J, 17(14), 1975-1985.

Pier. 2007. Pseudomonas aeruginosa lipopolysaccharide: a major virulence factor, initiator of inflammation and target for effective immunity. Int J Med Microbiol, 297(5), 277-295.

Plotkowski, et al. 1999. Pseudomonas aeruginosa internalization by human epithelial respiratory cells depends on cell differentiation, polarity, and junctional complex integrity. Am J Respir Cell Mol Biol, 20(5), 880-890.

Rada, et al. 2011. Reactive oxygen species mediate inflammatory cytokine release and EGFR-dependent mucin secretion in airway epithelial cells exposed to Pseudomonas pyocyanin. Mucosal Immunol, 4(2), 158-171.

Rahman. 2005. The role of oxidative stress in the pathogenesis of COPD: implications for therapy. Treat Respir Med, 4(3), 175-200. 
Rahman, \& Adcock. 2006. Oxidative stress and redox regulation of lung inflammation in COPD. Eur Respir J, 28(1), 219-242.

Rahman, \& MacNee. 1996. Role of oxidants/antioxidants in smoking-induced lung diseases. Free Radic Biol Med, 21(5), 669-681.

Rahman, \& MacNee. 2000. Oxidative stress and regulation of glutathione in lung inflammation. Eur Respir J, 16(3), 534-554.

Rath, \& Aggarwal. 1999. TNF-induced signaling in apoptosis. J Clin Immunol, 19(6), $350-364$.

Renaud, \& de Lorgeril. 1992. Wine, alcohol, platelets, and the French paradox for coronary heart disease. Lancet, 339(8808), 1523-1526.

Robb, et al. 2008. Molecular mechanisms of oxidative stress resistance induced by resveratrol: Specific and progressive induction of MnSOD. Biochem Biophys Res Commun, 367(2), 406-412.

Romero-Perez, et al. 1996. Levels of cis- and trans-Resveratrol and Their Glucosides in White and Rosé Vitis vinifera Wines from Spain. JOURNAL OF AGRICULTURAL AND FOOD CHEMISTRY, 44(8), 2124-2128. 
Sadikot, et al. 2005. Pathogen-host interactions in Pseudomonas aeruginosa pneumonia. Am J Respir Crit Care Med, 171(11), 1209-1223.

Saiman, \& Prince. 1993. Pseudomonas aeruginosa pili bind to asialoGM1 which is increased on the surface of cystic fibrosis epithelial cells. J Clin Invest, 92(4), 1875-1880.

Saliba, et al. 2006. Implications of oxidative stress in the cytotoxicity of Pseudomonas aeruginosa ExoU. Microbes Infect, 8(2), 450-459.

Santos, et al. 2011. New delivery systems to improve the bioavailability of resveratrol. Expert Opin Drug Deliv, 8(8), 973-990.

Santucci, et al. 2003. Infections in a burn intensive care unit: experience of seven years. J Hosp Infect, 53(1), 6-13.

Schroder, \& Harder. 1999. Human beta-defensin-2. Int J Biochem Cell Biol, 31(6), 645651.

Schwarzer, et al. 2008. Oxidative stress caused by pyocyanin impairs CFTR Cl(-) transport in human bronchial epithelial cells. Free Radic Biol Med, 45(12), 1653-1662.

Shakibaei, et al. 2008. Resveratrol suppresses interleukin-1beta-induced inflammatory signaling and apoptosis in human articular chondrocytes: potential for use as a novel nutraceutical for the treatment of osteoarthritis. Biochem Pharmacol, 76(11), 1426-1439. 
Shakibaei, et al. 2005. Curcumin protects human chondrocytes from IL-11beta-induced inhibition of collagen type II and beta1-integrin expression and activation of caspase-3: an immunomorphological study. Ann Anat, 187(5-6), 487-497.

Shek, et al. 1994. Liposomes in pulmonary applications: physicochemical considerations, pulmonary distribution and antioxidant delivery. J Drug Target, 2(5), 431-442.

Simon, et al. 2000. Role of reactive oxygen species (ROS) in apoptosis induction. Apoptosis, 5(5), 415-418.

Soleas, et al. 2001. Absorption of trans-resveratrol in rats. Methods Enzymol, 335, 145154.

Soleas, et al. 1997a. Resveratrol: a molecule whose time has come? And gone? Clin Biochem, 30(2), 91-113.

Soleas, et al. 1997b. Wine as a biological fluid: history, production, and role in disease prevention. J Clin Lab Anal, 11(5), 287-313.

Soleas, et al. 1995. Influences of viticultural and oenological factors on changes in cisand trans- resveratrol in commercial wines. Journal of Wine Research, 6(2), 107-121.

Stockley. 2002. Neutrophils and the pathogenesis of COPD. Chest, 121(5 Suppl), 151S$155 \mathrm{~S}$. 
Travassos, et al. 2005. Nod1 participates in the innate immune response to Pseudomonas aeruginosa. J Biol Chem, 280(44), 36714-36718.

Tsan, et al. 2000. Resveratrol induces Fas signalling-independent apoptosis in THP-1 human monocytic leukaemia cells. Br J Haematol, 109(2), 405-412.

Ungvari, et al. 2007. Resveratrol increases vascular oxidative stress resistance. Am J Physiol Heart Circ Physiol, 292(5), H2417-2424.

van den Dobbelsteen, et al. 1996. Rapid and specific efflux of reduced glutathione during apoptosis induced by anti-Fas/APO-1 antibody. J Biol Chem, 271(26), 15420-15427.

Vitrac, et al. 2003. Distribution of [14C]-trans-resveratrol, a cancer chemopreventive polyphenol, in mouse tissues after oral administration. Life Sci, 72(20), 2219-2233.

Vlahopoulos, et al. 1999. Nuclear factor-kappaB-dependent induction of interleukin-8 gene expression by tumor necrosis factor alpha: evidence for an antioxidant sensitive activating pathway distinct from nuclear translocation. Blood, 94(6), 1878-1889.

Vrhovsek, et al. 1995. The Occurence of Trans-Resveratrol in Slovenian Red and White Wines. Acta Alimentaria, 24(2), 203-212.

Walle, et al. 2004. High absorption but very low bioavailability of oral resveratrol in humans. Drug Metab Dispos, 32(12), 1377-1382. 
Ward. 2010. Oxidative stress: acute and progressive lung injury. Ann N Y Acad Sci, 1203, 53-59.

Wehkamp, et al. 2006. Pseudomonas aeruginosa- and IL-1beta-mediated induction of human beta-defensin-2 in keratinocytes is controlled by NF-kappaB and AP-1. J Invest Dermatol, 126(1), 121-127.

Winrow, et al. 1993. Free radicals in inflammation: second messengers and mediators of tissue destruction. Br Med Bull, 49(3), 506-522.

Winstanley, \& Fothergill. 2009. The role of quorum sensing in chronic cystic fibrosis Pseudomonas aeruginosa infections. FEMS Microbiol Lett, 290(1), 1-9.

Wood, et al. 2010. Antioxidant and anti-inflammatory effects of resveratrol in airway disease. Antioxid Redox Signal, 13(10), 1535-1548.

Yan, et al. 2008. Reactive oxygen species regulate Pseudomonas aeruginosa lipopolysaccharide-induced MUC5AC mucin expression via PKC-NADPH oxidaseROS-TGF-alpha signaling pathways in human airway epithelial cells. Biochem Biophys Res Commun, 366(2), 513-519.

Yu, et al. 2009. Effects of resveratrol on $\mathrm{H}(2) \mathrm{O}(2)$-induced apoptosis and expression of SIRTs in H9c2 cells. J Cell Biochem, 107(4), 741-747. 
